\title{
Comparison of Atmospheric Water Vapor in Observational and Model Data Sets
}

\author{
J.S. Boyle
}

\section{March 1, 2000}

U.S. Department of Energy

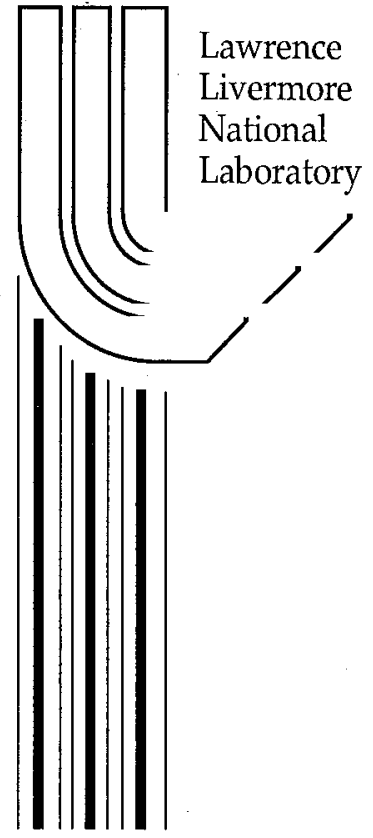




\section{DISCLAIMER}

This document was prepared as an account of work sponsored by an agency of the United States Government. Neither the United States Government nor the University of California nor any of their employees, makes any warranty, express or implied, or assumes any legal liability or responsibility for the accuracy, completeness, or usefulness of any information, apparatus, product, or process disclosed, or represents that its use would not infringe privately owned rights. Reference herein to any specific commercial product, process, or service by trade name, trademark, manufacturer, or otherwise, does not necessarily constitute or imply its endorsement, recommendation, or favoring by the United States Government or the University of California. The views and opinions of authors expressed herein do not necessarily state or reflect those of the United States Government or the University of California, and shall not be used for advertising or product endorsement purposes.

This report has been reproduced directly from the best available copy.

Available to DOE and DOE contractors from the Office of Scientific and Technical Information

P.O. Box 62, Oak Ridge, TN 37831

Prices available from (615) 576-8401, FTS 626-8401

Available to the public from the

National Technical Information Service

U.S. Department of Commerce

5285 Port Royal Rd.,

Springfield, VA 22161 


\title{
Comparison of Atmospheric Water Vapor in Observational and Model Data Sets
}

\author{
by \\ James S. Boyle \\ Program for Climate Model Diagnosis and Intercomparison \\ Lawrence Livermore National Laboratory \\ Livermore, CA USA
}

March 2000 


\begin{abstract}
The global water vapor distribution for five observational based data sets and three GCM integrations are compared. The variables considered are the mean and standard deviation values of the precipitable water for the entire atmospheric column and the 500 to $300 \mathrm{hPa}$ layer for January and July.

The observationally based sets are the radiosonde data of Ross and Elliott, the ERA and NCEP reanalyses, and the NVAP blend of sonde and satellite data. The three GCM simulations all use the NCAR CCM3 as the atmospheric model. They include: a AMIP type simulation using observed SSTs for the period 1979 to 1993, the NCAR CSM 300 year coupled ocean - atmosphere integration, and a CSM integration with a $1 \% \mathrm{CO} 2$ increase per year.

The observational data exhibit some serious inconsistencies. There are geographical patterns of differences related to interannual variations and national instrument biases. It is clear that the proper characterization of water vapor is somewhat uncertain. Some conclusions about these data appear to be robust even given the discrepancies. The ERA data are too dry especially in the upper levels. The observational data evince much better agreement in the data rich Northern Hemisphere compared to the Southern. Distinct biases are quite pronounced over the Southern Ocean. The mean values and particularly the standard deviations of the three reanalyses are very dependent upon the GCM used as the assimilation vehicle for the analyses. This is made clear by the much enhanced tropical variability in the NCEP/DOE/ AMIP reanalyses compared the initial NCEP/NCAR Reanalysis.

The NCAR CCM3 shows consistent evidence of a dry bias. The $1 \% \mathrm{CO} 2$ experiment shows a very similar pattern of disagreement with the sonde data as the other integrations, once account is taken of the warming trend. No new modes of difference are evident in the 1\% CO2 experiment. All the CCM3 runs indicated too much Tropical variability especially in the western Tropical Pacific and Southeast Asia.

A EOF analysis of the interannual variations of the zonally averaged precipitable water and the 500 to $300 \mathrm{hPa}$ layer reveals fundamental differences in the structure of the variations. The impact of ENSO and variations of the ITCZ have only a low level of correspondence between the observed data, much less the simulations.

It is apparent that an adequate characterization of the climatology of the global water vapor distribution is not yet at hand.
\end{abstract}




\section{Introduction}

The distribution of water vapor in the atmosphere in a real sense is what makes weather and climate. Water vapor is the most active greenhouse gas and through feedbacks exerts a powerful influence on the climate system. Details of the distribution are undergoing even closer examination in the context of global warming studies. In order to assess the magnitudes and nature of the vapor feedbacks the distribution both horizontally and vertically must be known to a fairly high degree of accuracy, more accurately than it is now known. The second IPCC assessment (IPCC 1995) states that "Feedback from the redistribution of water vapor remains a substantial uncertainty in climate models". Confounding the uncertainty in modeling is the uncertainty in the observations. Ross and Elliot (1996) document the considerable problems with the measurement of vapor in the radiosonde network. Regional and temporal variations in the observations indicate serious inhomogeneties in the radiosonde archive. Soden and Lanzante (1996) describe the significant differences in satellite derived estimates of upper tropopspheric humidity and the difficulties in reconciling these differences in light of the radiosonde uncertainties.

This paper compares the monthly mean water vapor content in five global, observationally based data sets and three integrations of the NCAR Community Climate Model 3 / Climate System Model (CCM3/CSM). Differences in the observational data sets provide a context in which to evaluate the products of the GCM integrations.

In the next section the observationally based data sets will be described, this will be followed by a brief summary of the general circulation model (GCM) simulation data. Section 4 compares the January and June mean and standard deviations of columnar and layer precipitable water across all the data sets. The next two sections will review the annual cycle (January - July) and a empirical orthogonal function (EOF) analysis of the interannual variations. The last section will be a brief discussion and some conclusions.

\section{Observationally Based Data}

\section{a. Radiosonde}

Radiosonde data for all its known shortcomings, is still the standard against which other products are often judged. Although some remote sensing techniques are 
proving to be valuable, none of these recently implemented monitoring devices can supply the long time record of the sonde data. The sonde data offer the longest record of water vapor measurement and are often used in the development of algorithms for remote sensed data. The radiosonde data set used here is that of Ross and Elliot (1996), hereafter RE. These data are monthly climatological means and standard deviations for the time period 1973 to 1995 . These data have been subjected to an extensive quality control described in the reference. The control procedures can eliminate egregiously erroneous values but cannot overcome the subtle systematic biases in the measurement instruments themselves. These possible biases in the data are fully discussed in RE, and will be brought up when discussing the results. For the mean values we used the means generated from the 00 and $12 \mathrm{Z}$ values, the standard deviations used the 00Z data only as supplied in the RE data base. The data files provided seven layer precipitable water values for the following layers: Surface to $850 \mathrm{hPa}, 850$ to $700 \mathrm{hPa}, 700 \mathrm{hPa}$ to $500 \mathrm{hPa}, 500 \mathrm{hPa}$ to $300 \mathrm{hPa}$, surface to $700 \mathrm{hPa}$, surface to $500 \mathrm{hPa}$, surface to $300 \mathrm{hPa}$. Data above $300 \mathrm{hPa}$ was considered to be too unreliable to contribute any useful information.

\section{b. Satellite/Rawindsonde}

The NASA Water Vapor Project (NVAP) is a blending of satellite remote sensed and rawindsonde data. The procedures for blending are described and Randel et al. (1996). These data are in the form of monthly means and are available for the period 1988 to 1994 . The data used here were obtained from the GEWEX CDROM. Note that the rawindsonde data used in the blending procedure is identical to that of Ross and Elliot (see above) for the 1988 to 1994 period. The analysis combines the retrievals from the TIROS Operational Vertical Sounder (TOVS) and the Special Sensor Microwave/Imager (SSM/I) with the radiosonde observations. The satellite data have their own limitations. The SSM/I is only available over ocean regions and only produces vertically integrated vapor values. The TOVS data encounter difficulties in unambiguously determining cloud free regions in which the retrieval algorithm is valid.

These data provide the columnar integrated values and well as layer precipitable water for the Surface to $700 \mathrm{hPa}, 700$ to $500 \mathrm{hPa}$, and 500 to $300 \mathrm{hPa}$ layers. Only the TOVS and radiosonde data provided information for the individual layer water vapor.

\section{c. Reanalyses data sets:}


The products of three reanalyses efforts are used. The basic idea behind the reanalyses is to process observational data using the same assimilation model and techniques over the duration of the analysis period. This is in contrast to the analyses produced by the constantly changing operational assimilation systems. Reanalyses can only keep the assimilation tools constant, it cannot alter the fact that the nature and distribution of the input data is continually evolving. The reanalyses used are:

European Centre for Medium Range Forecast Re-Analysis (ERA). This spans the period from 1979 to 1993 and is described by Gibson et al. (1997).

The NCEP/NCAR Reanalyses. (NCEP) spans the time period from 1948 to 1998. Only the 1979 to 1993 subset is used here. The procedures for these data are described by Kalnay et al. (1996).

The NCEP/AMIP-II DOE (NCEP2) Reanalysis spans the time period from 1979 to 1994 . The subset of 1979 to 1993 is used here. This reanalysis is an effort to correct some errors made in navigation of the input data and specification of boundary forcing during the original NCEP reanalyses. In addition, some significant changes were made to the assimilation model, Kanamitsu et al. (1999).

\section{d. Discussion}

There are several reasons why the observationally based data might differ:

(1) Different time periods. An attempt was made to maximize the amount of overlap for the observed data sets, but there are still large mismatches. Differences can be attributed to interannual variations and changing instruments and procedures. The short time duration of the NVAP data adversely affects the estimate of the variability. The NCEP and NCEP2 reanalyses share the same time frame as the ERA, 1979 to 1993.

Trenberth and Hurrel (1994), Trenberth (1995) and Zhang et al. (1997) indicate that there was a secular change in the global circulation occurring in the late 70 's. The Southern Oscillation Index (not shown) shows evidence of a break about 1978, with more frequent and intense ENSO events occurring after this time. Thus, the RE data which spans this change might have systematic differences from data set which are sampled after 1979, such as the ERA, NVAP and NCEP.

(2) Different input data for re-analyses:

The ERA and NCEP processed the satellite data in very different ways and used 
different quality control procedures on the conventional observations. The NCEP2 used exactly the same data as NCEP but corrected some navigation errors. These errors were especially serious in the Southern Hemisphere where there is little other data to compensate. Over the continents the radiosonde data should be quite similar to Ross and Elliott in all the reanalyses.

(3) Different Assimilation models and techniques for the re-analyses. Even if the input data were identical, there would be differences in the analyses due to the specific model used in the assimilation. This effect should be most evident in data sparse region, where the model forecast may not be strongly modified by the data in the analysis step.

\section{Model Integration Data:}

The three GCM integrations all use a common atmospheric component, the NCAR CCM3. The first is an Atmospheric Model Intercomparison Program (AMIP) type simulation using the CCM3 with prescribed observed sea surface temperatures (SST) for the period 1979 to 1993. The prescribed SST are the same as those used in the NCEP reanalysis. The second is the NCAR Climate System model, experiment b003 (http://www.cgd.ucar.edu/csm/experiments/b003.html) which was a 300 year integration, hereafter referred to as CSM. This is a fully coupled climate model involving atmospheric and oceanic GCMs and land and ice models. The years $16-35$ are chosen for analysis, just to give a sampling of the climatology of the model. This is also the period described by Meehl and Arblaster (1999).

The third is a 125 year integration of the CSM in which the $\mathrm{CO}_{2}$ concentration increases at $1 \%$ per year(http://www.cgd.ucar.edu/csm/experiments/b006.html), hereafter referred to as CSMb6. This results in a global mean temperature increase of 2.25 $\mathrm{K}$ at the end of the integration. The last 20 years of this data set are used here, yielding a maximum $\mathrm{CO}_{2}$ effect.

The model integrations each contribute to a different aspect of the climate modeling question. The CCM3 AMIP integration used the observed SSTs for the period from 1979 to 1993 as boundary conditions. To the extent that the ocean temperatures control the climate, this integration should resemble the observations for the coincident period. The CSM coupled simulation has no constraint to resemble the observational data, except in a climatological sense. The CSM ocean simulation has 
documented shortcomings in the tropical variability, Meehl and Arblaster (1999). The increasing $\mathrm{CO}_{2} \mathrm{CSM}$ experiment increases the global mean surface temperature by a substantial amount. As in the CSM run the ocean temperatures are not constrained in any way. This run will provide some idea of the types of changes in water vapor content produced by this global warming scenario.

\section{Results}

\section{a. Total Precipitable Water January and June Means and Standard Deviations}

Figure 1 depicts the mean January precipitable water values for the Ross and Elliott data and the differences of the Ross and Elliott value from the specific data set normalized by the radiosonde value and expressed as a percent. The blue indicates negative values which indicates that the data set value is less than the radiosonde. The red indicates positive values which indicates that the data set value is greater than the radiosonde value.

The seasonal variation of the sonde data, Fig. 1a, presents an expected picture. Small values are evident in the winter hemisphere and over the continents, while higher values prevail in the summer hemisphere, the Tropics and over the oceans. The dramatic unevenness in the spatial sampling of the radiosonde network is clear in this figure. The NVAP differences, Fig. 1d, are generally the smallest of the observed sets, except in regions where the satellite data makes a dominant contribution.

The pattern over the continents reveals a problem noted by Soden and Lazante (1996). They found that geographical regions of over and under estimates of precipitable water could be correlated with the type of humidity sensor used in the region.. The slower responding sensors in the former Soviet Union (FSU), eastern Europe, China and India tend to produce values of upper tropospheric humidity higher than the TOVS estimates. This type of error is greater with colder temperatures, and thus increases with height and latitude. January with its low vapor values should be the worst case for the Northern Hemisphere with respect to sensor systematic errors. Ross and Elliott point out that by changing the type of sensor from a slow responding to a fast response can result in apparent drying in the time series of measurements after the changeover. They note that there were many stations that changed the type of sensor through the 1980s. The differences in Fig. 1d, would appear to be a combination of the slow sensor problem and the changeover effect. If China retained the 
slow sensors it would have the systematic over estimate to the data corrected using the TOVS retrievals. If the FSU changed over to the new sensors it would display an underestimate to means generated using 1988 to 1994 NVAP data. Of course, these inhomogeneities of sensors are overlain onto the natural variability that will be found comparing 1973-95 means to those for 1988-94. Figure 1d points out the difficulties in assessing moisture fields with any degree of confidence.

Both the ERA and NCEP tend to underestimate the precipitable water with respect to the radiosondes. The magnitude of the ERA underestimate indicates that this analyses is definitely drier, even beyond the rather generous uncertainties hinted at in Fig. 1d. NCEP appears to be slightly dry but is closer to the NVAP fields than the ERA.

The CCM3 and CSM integrations in general underestimate the values in a manner similar to the ERA. The CSM is especially dry. The pattern of biases for the large part remain similar in the two integrations. As might be expected the CSMb6 experiment has a somewhat wetter bias, this appears to be emphasized in the Southern Hemisphere.

Notice that there is a persistent pattern across the NCEP, NVAP, CCM3, and CSM data sets, Figures $1 b, c, d, e, f$. This is manifested by a dipole across the US, the west being negative and the east positive, by positive values in Japan, but negative west of Japan stretching into southern Europe and the Middle East. This might be attributable to a difference in the climatology of the time periods. The radiosonde data has six years from 1973 to 1978, before the switch to more frequent, intense ENSO events after 1979. The sonde data will differ from the other sets in the intensity of an ENSO perturbation. Yet the fact that the pattern is also manifest in the CSM, which has no such relation to these events undercuts this theory. The persistent pattern across all the data sets including the CSM indicates that the sondes' bias as the instruments changed through the time period have imprinted an artifact on the pattern. The ERA is too dry while the CSMb6 is too wet to depict the pattern with any fidelity.

Figure 2 is the same as Fig. 1 except it depicts the July mean values. The geographic bias seen in Fig. 1d is not as apparent in Fig. 2d, which could be anticipated since the instrument errors are most evident at low values of moisture. The higher values of July precipitable water in the Northern Hemisphere will tend to minimize the inhomogenietires in the instruments. The NVAP differences are in general re- 
duced in Fig. 2d, with some larger errors found in the winter hemisphere over Australia and South Africa.. The two reanalysis' both appear to have a distinct dry bias despite some limited regions of opposite sign.

The model simulations all evince a general Northern Hemisphere dryness, even in the $\mathrm{CO}_{2}$ experiment, Fig. 2g. The b006 run is wetter than the CSM simulation, so that it is more in line with the CCM3 result.

The only consistent pattern across all the data sets is dryness over the Northern Continents. The artifact seen in January data is not evident, the higher July values in the Northern Hemisphere may not allow the dry bias to be clearly shown.

In Figures 1 and 2 the stations in northern South America and Central America show a consistent dryness with respect to all the other data sets. This might be attributed to ENSO which gained in strength and frequency after 1979 and biased means using data taken outside this time period. However, the dryness is even evident from the CSM, which has no increase in ENSO events and seriously underpredicts the strength of the events it produces. This indicates some systematic problem with these stations.

Figure 3. The same as Fig. 1, except for the standard deviation of the January precipitable water. In this figure the NVAP are substantially different from Ross and Elliott. Over land this must be at least in part, attributed to the difference in time period and duration of the two data sets. From purely statistical ground one would anticipate that the NVAP would systematically underestimate the standard deviation if the time series of precipitable water were stationary. From statistics it might be estimated that the NVAP values should be about a factor of three less than the Ross and Elliott. The NVAP values in Fig. 3 are generally somewhat less than this value. It should be noted that most of the overestimates occur where the satellite data might have a significant contribution. This problem does cloud some of the conclusions that can be drawn for the reanalyses data sets. The ERA appears to be a bit less variable over the northern landmasses.

The model simulations evince an overly active January. There is some geographical variation across the northern landmasses, but here it is less obvious whether this is a observational problem or due to the model shortcomings in specific climate regimes. The maritime continent region seems too active in all the simulations. There are regions such as the USA, and eastern Asia where the CCM3 variability pattern is enhanced progressively as one goes from the CSM to the CSMb006. 
There are one or two station in India where the ratios, Figs. $3 \mathrm{~b}$ to $3 \mathrm{~g}$, are very large. This is due to the observed standard deviation being anomalously small at these locations. This is likely to be an error in the data.

Figure 4 is the same as Fig. 3, except for July. The conclusions drawn from the three observational sets are similar to those made for the January data. Although the NVAP seems to have a greater number of overestimates. Both NCEP and ERA tend to underestimate the variability exceptions are the monsoon regions of southeast Asian and the southwest US. The patterns of the NCEP and ERA are similar.

The CCM3 shows a serious overestimate of the variability in southeast Asia, which extends to the west equatorial Pacific in the CSM. It would seem that it is a fairly sure conclusion that this model is too active over South East Asia. The CSMb6 run exhibits a systematic amplification of the high variability regions of the CCM3, with the underestimate regions remaining about the same.

\section{b. $500-300$ hPa Layer Precipitable Water January and June Means and Standard} Deviations

Figure 5 displays the water vapor content for the 500 to $300 \mathrm{hPa}$ layer. The measurement of this quantity is fraught with uncertainty. The sonde based sensors perform poorly in the cold, dry upper regions of the atmosphere. The satellite retrievals are rather inexact in slicing out a particular layer of moisture as opposed to an entire column estimate at which they are quite good. The SSM/I cannot provide information for layers, so only the TOVS data are used in the satellite estimate of the layers. As described by RE, the sonde measurement problems are confounded by substantial differences in national reporting procedures at height. These procedures attempt to address the measurement shortcomings in the colder regions, but add an additional level of temporal inhomogeneity as the procedures are revised.

The amount of vapor at these levels is substantially less than the columnar value. The scale in Fig. $5 a$ is a factor of 16 less than Fig. 1a. The NVAP values are almost all greater than the RE. The negative points are over the FSU and India, which probably indicate a sonde instrument problem. The fact that the rest of the stations are positive, would appear to support a general increase in the NVAP time period, or a underestimate for this level by the sondes with respect to the TOVS retrivals. The NCEP actually agree more closely to RE than does the NVAP. The ERA stands out as 
grossly drier than all of the observational sets of data.

The model runs are too wet in the Southern Hemisphere and Tropics, except for SE Asia and too dry over Asia. There is a progression from the CCM3 to CSMb006 of this layer becoming increasingly more moist but retaining a similar pattern.

Figure 6 is as in Fig. 5 except for July. The NVAP data agree fairly well with the $\mathrm{RE}$ in the northern Hemisphere while it is substantially greater in the winter hemisphere. This might to due to the TOVS measurements dominating in the Southern Hemisphere and the TOVS values being somewhat greater than the sonde data in the winter. The ERA again stands out as the driest.

The pattern of the model simulations stays similar, with the CSMb006 being the wettest of the sequence. The CCM3 appears to have some anomalous values over the Red Sea, Arabian Peninsula.

Figure 7 is as in Fig. 3 except for the 500 to $300 \mathrm{hPa}$ layer. The variations are similar to those of the columnar value, the largest values being in the Tropics and Southern sub-Tropics. The NVAP differences appear to be less geographically oriented, but more related to the position of the mean jet and thus the tropopause. Perhaps, variations in the tropopause in the winter hemisphere are different in the 88-94 period. The NCEP appears to have the most consistent agreement with the RE data. The ERA is consistently too dry. The models tend to have too much variability in the Tropics and monsoon regions compared to the sonde data..

Figure 8 is as in Fig. 4 except for the 500 to $300 \mathrm{hPa}$ layer. As in the previous figure, generally the same comments apply to this level as the columnar values in Fig. 4.

\section{c. Global Latitudinal Averages}

In the following figures, the gridded data are averaged in latitude bands about the globe so that all the sets can be easily compared for different regions. This provides a visually direct comparison on a single plot.

Shown in Fig. 9a are plots of the mean July (Northern summer) precipitable water values averaged from $35 \mathrm{~N}$ to $45 \mathrm{~N}$ around the globe. All the data sets are shown, the radiosondes are binned into 5 degree longitude bands before the latitudinal mean is taken. It must be noted that in many regions the radiosonde data may only include 
a few stations or one or none. If the stations are located at an extreme of the latitude bounds, it can provide a misleading value compared to the means of the gridded fields due to the large latitudinal gradients in moisture. Despite this strong caveat, it was felt that the RE data provides some perspective.

The model runs, CSM, CCM3, CSMb6, tend to be consistently at the extremes of the plot either maxima or minima at specific longitudes but not consistently at either extreme. The agreement of models and observations appears to be about on a par with the agreement between the various observational estimates. At about 70W, all the models are too low with respect to the observations, while in the mid Pacific at 180E the CSMb6 is highest and CCM3 and CSM are the lowest. Overall the observational sets evince good agreement. An exception is over the very high terrain from $60-100 \mathrm{E}$, where NVAP and RE are somewhat higher.

Figure $9 \mathrm{~b}$ is the same as 9a except averaged for January (Southern summer) from $60 \mathrm{~S}$ to $40 \mathrm{~S}$, the region of the Southern Ocean. In this data void there is a substantial spread between the observational data sets. Each one appears to display a characteristic bias which offsets it from the others with longitudinal variations showing a good correlation. Apparently, in this data void region, the biases of the assimilation models are laid bare. The $\mathrm{RE}$ data show a sparse distribution and most of these are from Antarctica. The GCM integrations fall into a ordering similar to the northern latitudes. The NVAP data which would be purely satellite estimates are consistently the lowest values by a large margin. This was not true over the Northern oceans in Fig. 9a. Careful examination, indicates that the ERA, NCEP and NVAP have a similar ordering over the oceans in $9 \mathrm{a}$, but the difference in emphasized in $9 \mathrm{~b}$.

In the winters of both hemispheres, Fig. 9cd, the values are somewhat reduced. In the northern hemisphere the cold air over the continents leads to very low moisture content. Over the Pacific the peak shifts to the eastern side of the ocean with the NCEP reanalyses having a higher peak than the ERA and NVAP. The southern hemisphere has less dramatic change in structure. The ERA is consistently the lowest, switching places with the NVAP from the summer. The impact of the $\mathrm{CO}_{2}$ warming is a great deal more pronounced in the Southern Hemisphere. The CSM and CSMb6 have a large and consistent offset in Figs. $9 \mathrm{~b}$ and $9 \mathrm{~d}$.

Figure10 a,b is the same as $9 \mathrm{a}, \mathrm{b}$ except for the 500 to $300 \mathrm{hPa}$ layer. In the northern Hemisphere, the differences over the oceans are more pronounced, than for the 
total column value. The sonde values seem to tie the observed data sets together over the land. The NVAP shows less longitudinal variation than the other sets and varies somewhat less between the Southern summer, Fig. 10b, and winter, Fig. 10d. This is not at all evident in the NVAP values for the Northern hemisphere, and might be due to the higher latitudes selected in the Southern plots.

Figure 11 depicts the standard deviation of precipitable water averaged around the globe from $10 \mathrm{~N}$ to $10 \mathrm{~S}$ for January and July. For these data the NCEP and NCEP2 show substantial differences, especially in January. One reason for modifying the assimilation model in the NCEP2 reanalyses was to improve the tropical variability of the analyses. To a large extent the data input in this latitude band was identical between NCEP and NCEP2, what is seen here is the impact of the assimilation model in a data sparse region. The NCEP2 curve agrees more closely with the other observational data sets, although it is less than ERA in June and July and less than NVAP in July. Both CSM integrations markedly shift the peak of activity in both January and July westward, this might be due to the tendency of the ocean model in these integrations to form a tongue of anomalously cool water along the Equator in the eastern Pacific.

Figure 12 is the same as Fig. 11 except for the 500 to $300 \mathrm{hPa}$ layer. The data were not available to compute this quantity for the NCEP2. The models tend to show the most longitudinal variation. There is poor agreement as to the location and magnitude of the peaks although there is a tendency for maxima in the western Pacific. The NVAP data are consistently less than all the others. The NCEP and ERA display only modest agreement.

\section{Annual Cycle}

Shown in the upper figure of Fig. 13 is the difference between the July and January precipitable water averaged from $25 \mathrm{~N}$ to $35 \mathrm{~N}$. This latitude band was chosen since it encompassed regions which exhibited the largest amplitude of annual cycle in the Northern Hemisphere. The agreement between the observed data set is fair, the model integrations tend to underestimate the amplitude except from 0 to $120 \mathrm{E}$.

The lower figure is the same as the first except for the latitude band $20 \mathrm{~S}$ to $10 \mathrm{~S}$. The agreement between the observational sets is not as good as in the Northern Hemisphere, especially in the eastern Pacific. The models tend to underestimate the amplitude of the cycle in Fig. 13a and this carries over to the Southern Hemisphere for CCM3 and csmb6 but not the CCM3. the models all underestimate the annual cy- 
cle over North America, 240E to 300E.

Figure 14 is the same as Figure 13 except for the 500 to $300 \mathrm{hPa}$ layer. The Northern Hemisphere (top graph) show good agreement of all the data sets, with only the CCM3 showing eccentric behavior. In the southern hemisphere (bottom figure), the model tend to be the extreme, being too large over the oceans and too small over the land. The ERA tends to have greater amplitude over most of the curve.

\section{d. EOF Analysis of Zonal Mean Interannual Variations}

Figure 15 presents leading mode of a EOF of the covariance matrix of the zonally averaged precipitable water weighted by the cosine of latitude for each of the global data sets. The fraction variance accounted for by this mode is indicated in Table 1 . Notice the large variation in the observed data sets with respect to the structure about the Equator. The differences are pronounced in the southern hemisphere. The variance explained by the leading mode also varies substantially. An analysis of the time series indicates that the variations are linked closely to the Nino 3/4 SST. The large differences in the variance explained indicates a wide variation in the impact of the SSTs on the vapor distribution on the data sets.

The lower figure is the same as the upper except for the 500 to $300 \mathrm{hPa}$ layer water vapor. The NCEP2 is not used in this figure, since only the columnar values were available. As above there is a substantial variation in the structure of the observational data sets. The model runs show a very different structure from any of the observations about the Equator. Further analysis shows that this is due to differences in the locations of the ITCZ and its concomitant convection. For this highly averaged field the differences in the structure of the interannual variations is very large, indicating very different modes of variation for the water vapor distribution in this key area.

\section{Discussion and Conclusions}

The story told by consideration of the data presented here is one of caution in trying to evaluate the distribution of water vapor over the globe. The prospects for a reliable, global data set spanning the last two to three decades are not promising. A positive results is that the various observationally based data sets appear to be in fair 
agreement over the (comparatively) data rich northern hemisphere, this is true even over the Pacific Ocean. The data poor regions of the southern Hemisphere show serious biases for each analysis technique. Thus, it appears that the assimilation system can fill in the data void regions to a fair extent if provided with timely updates on the periphery of the voids. The fact that the analyses vary substantially in regions where the observations are sparse in space and time indicates the gap in providing a global vapor distribution. Comparing the NCEP and NCEP2 reanalyses standard deviation of precipitable water along the Equator, Fig. 11, it is shown how dramatically the variability can be a function of the assimilation model in such analyses. The data going into the two analyses in identical for this region, the difference seen in the figures is the result of a conscious effort to enhance the variability of the model used in the assimilation.

The distinct patterns of anomalies with respect to the sonde data seen in Figs. 1, 2 and following indicates the probable inhomogenieties in the sonde observations. These artifacts are the result of instrument biases, changes in instrumentation, changes in reporting procedures and processing procedures. As indicated in RE it is not clear that the documentation exists to be able to compensate for all these contributing factors.

A summary of conclusions are:

1. There are substantial differences in the mean and standard deviation between observationally based data sets.

2. There are geographical patterns when the data sets are compared to sondes, which indicate regional inhomogenieties in the data records of water vapor.

3. These differences become more severe with height.

4. There are distinct biases in the reanalyses vapor products in data void regions, such as the Southern Ocean.

5. The model integrations considered here are generally outliers with respect to the observed global data sets.

6. Characteristic atmospheric GCM biases are common to the prescribed SST and coupled model integrations. This model appears to be much too variable in the Tropics.

7. The $1 \%$ per year $\mathrm{Co} 2$ increase integration displays the same patterns of errors as the uncoupled and coupled simulations with the vapor amount amplified. No new unique modes were obvious. 
8. An EOF analysis of the zonally averaged interannual anomalies indicate that there are very pronounced differences in the basic structure of the interannual variation about the equator. This becomes more prominent at the 500-300 $\mathrm{hPa}$ layer. The models have a nearly unique structure apart from that of the observations.

Acknowledgements: This work was performed under the auspices of the Department of Energy Environmental Sciences Division by the Lawrence Livermore National Laboratory under contract W-7405-ENG-48. NCEP Reanalysis precipitable water data was obtained from The Climate Diagnostics Center. The radiosonde data was obtained from the Air Resources Laboratory ftp site - ftp://gus.arlhq.noaa.gov/pub/ climate/W_climatology/. The NVAP data was obtained from the NASA Water Vapor Project Global Energy and Water Cycle Experiment CD. The CCM3 and CSM data was obtained from the NCAR CSM web site - http://www.cgd.ucar.edu/csm/. 


\section{References}

Boville, B. A., and P. R. Gent, 1998: The NCAR Climate System Model, Version One., J.Climate, 11, 1115-1130.

Boville, B. A., and J. W. Hurrel, 1998: A comparison of the atmospheric circulations simulated by the CCM3 and CSM1., J. Climate, 11, 1327-1341.

Gibson, J. K., P. Kallberg, S. Uppla, A. Hernandez, A. Nomura, and E. Serrano, 1997: ECMWF Re-Analysis Project Report Series. 1. ERA Description. 66p.

Intergovernmental Panel on Climate Change, 1995: Climate Change 1995: The Second IPCC Assessment. Cambridge University Press, 572pp.

Kalnay, E. M., M. Kanimitsu, R. Kistler, W. Collins, D. Deaven, L. Gandin, M. Iredell, S. Saha, G. White, J. Woolen, Y. Zhu, M. Chelliah, W. Ebisuzaki, W. Higgins, J. Janowiak, K. C. Mo, C. Ropelewski, J. Wang, A. Leetma, R. Reynolds, R. Jenne and D. Joseph, 1996: The NCEP/NCAR 40-year reanalysis project. Bull. Amer. Met. Soc., 77, 437-471.

Kanamitsu, M., W. Ebisuzaki, J. Woolen, J. Potter, M. Fiorino, 1999: An Overview of Reanalysis - 2. Second Internationals Conference on Re-Analyses. 23-27 August, 1999. Reading, U.K. ( also available at http://wesley.wwb.noaa.gov/ranalysis2/).

Kiehl, J. T., J.J. Hack, G. B. Bonan, B.A. Boville, D. L. Williamson, and P. J. Rasch, 1998: The National Center for Atmospheric Research Community Climate Model: CCM3., J. Climate, 11, 1131-1149.

Meehl, G. A. and J. M. Arblaster, 1998: The Asian-Australian Monsoon and El Nino Southern Oscillation in the NCAR Climate System Model. J. Clim, 11, 13561385.

Weatherly, J. W., B. P. Briegleb, W. G. Large, and J. A. Maslanik, 1998: Sea ice and polar climate in the NCAR CSM., J. Climate, 11, 1472-1486.

Ross, R. J. and W. P. Elliott, 1996: Tropospheric Precipitable Water: A RadiosondeBased Climatology. NOAA Technical Memorandum ERL ARL-210. U.S. Dept. of Commerce.

Randel, D. L., T. H. VonderHaar, M. A. Ringerrud, G. L. Stephens, T. J. Greenwald, C. L. Coombs, 1996: A new global water vapor data set. Bull. Amer. Meteor. Soc., 77, 1233-1246.

Trenberth, K. E., 1990: Recent observed interdecadal climate changes in the Northern Hemisphere, Bull. Amer. Meteor. Soc, 71, 988-993. 
Trenberth, K. E. and J. Hurrel, 1994: Decadal atmosphere-ocean variations in the Pacific., Clim. Dyn, 9, 303-319.

Trenberth, K. E., 1995: Atmospheric circulation changes. Clim. Change, 31, 427-453.

Wang, B., 1995: Interdecadal changes in El Nino onset in the last four decades. $J$. Clim.,8,267-285.

Zhang, Y., J. M. Wallace and D. S. Battisti, 1997: ENSO-like interdecadal variability:1900-93, J. Clim, 10, 1004-1020. 
Table 1: Percent variance explained by leading EOF of zonally averaged precipitable water and precipitable water for the 300 to $500 \mathrm{hPa}$ layer.

\begin{tabular}{|l|l|l|l|l|l|l|l|l|} 
Columnar Precipi- & 28 & 66 & 43 & 37 & 46 & 33 & 30 \\
table water \\
$\begin{array}{l}\text { Precipitable water } \\
300 \text { to } 500 \mathrm{hPa}\end{array}$
\end{tabular}



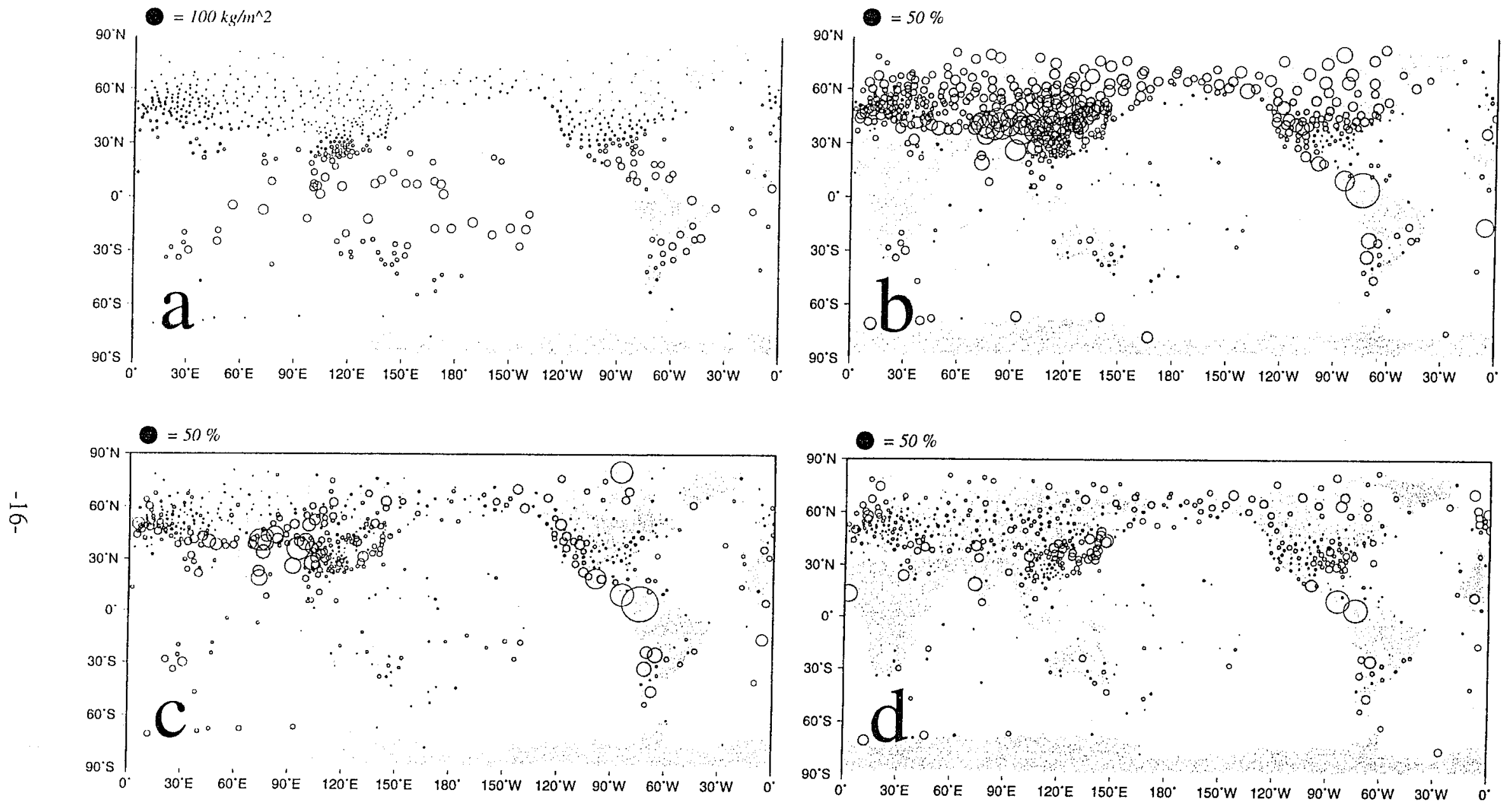

Figure 1. Mean January precipitable water values for (a) Ross and Elliott radiosonde data. The values are indicated by the size of the circle shown above the left ahnd side of the frame.

(b) The difference of the ERA minus the Ross and Elliott precipitable water, normalized by the radiosonde value and expressed as a percent. The values are indicated by the size of the circle scale shown above the left hand side of the frame. Blue indicates negative values, red indicates positive values.(c) As in (b) except for the NCEP reanalysis(d) As in (b) except for the NVAP data set. 

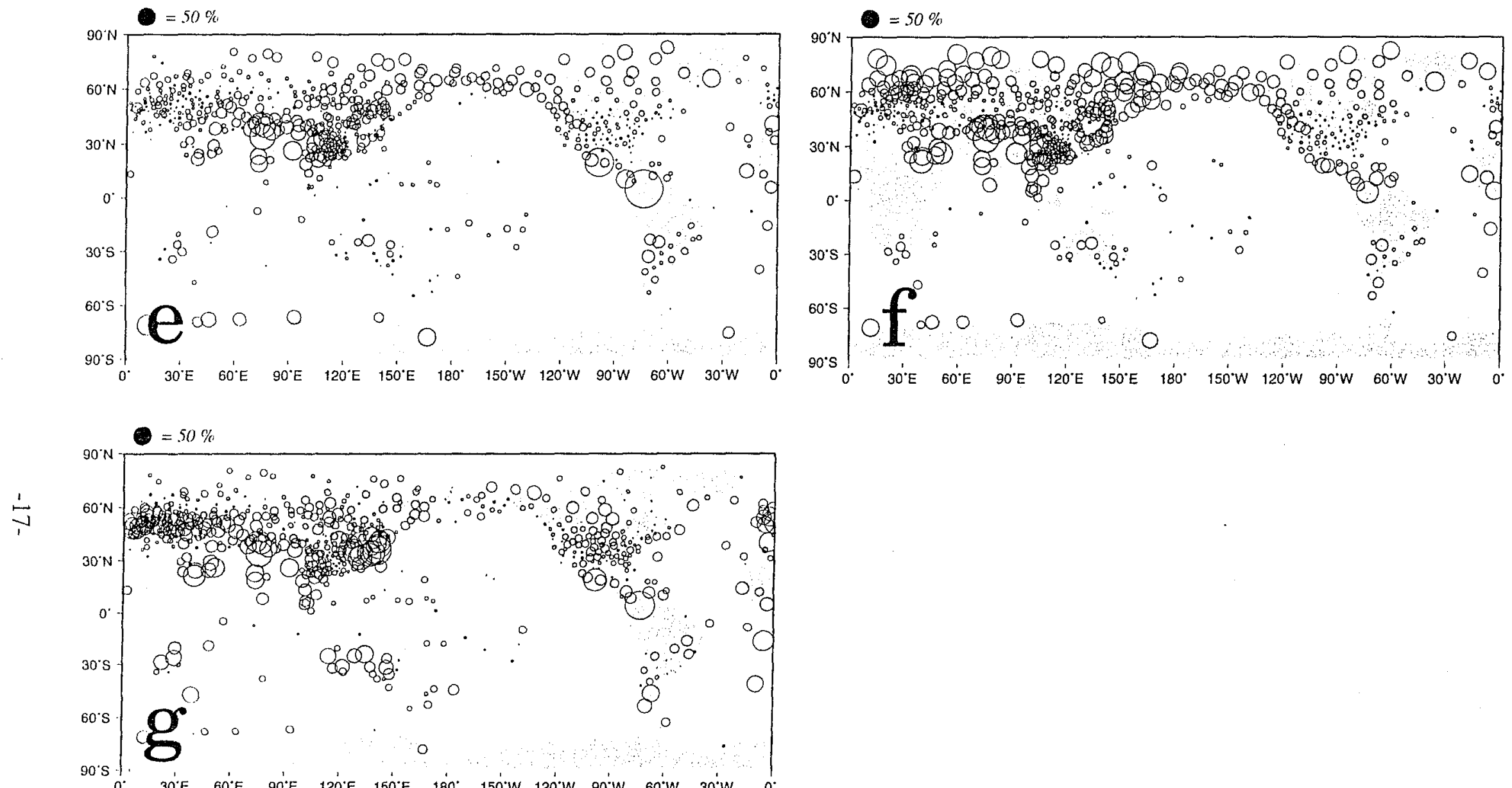

Figure 1. (cont'd) (e) As in (b)except for the CCM3 AMIP integration. (f) As in (b) except for the CSM control integration.(g) As in (b) except for the $\mathrm{CSM} 1 \%$ per year $\mathrm{CO}_{2}$ increase experiment. 

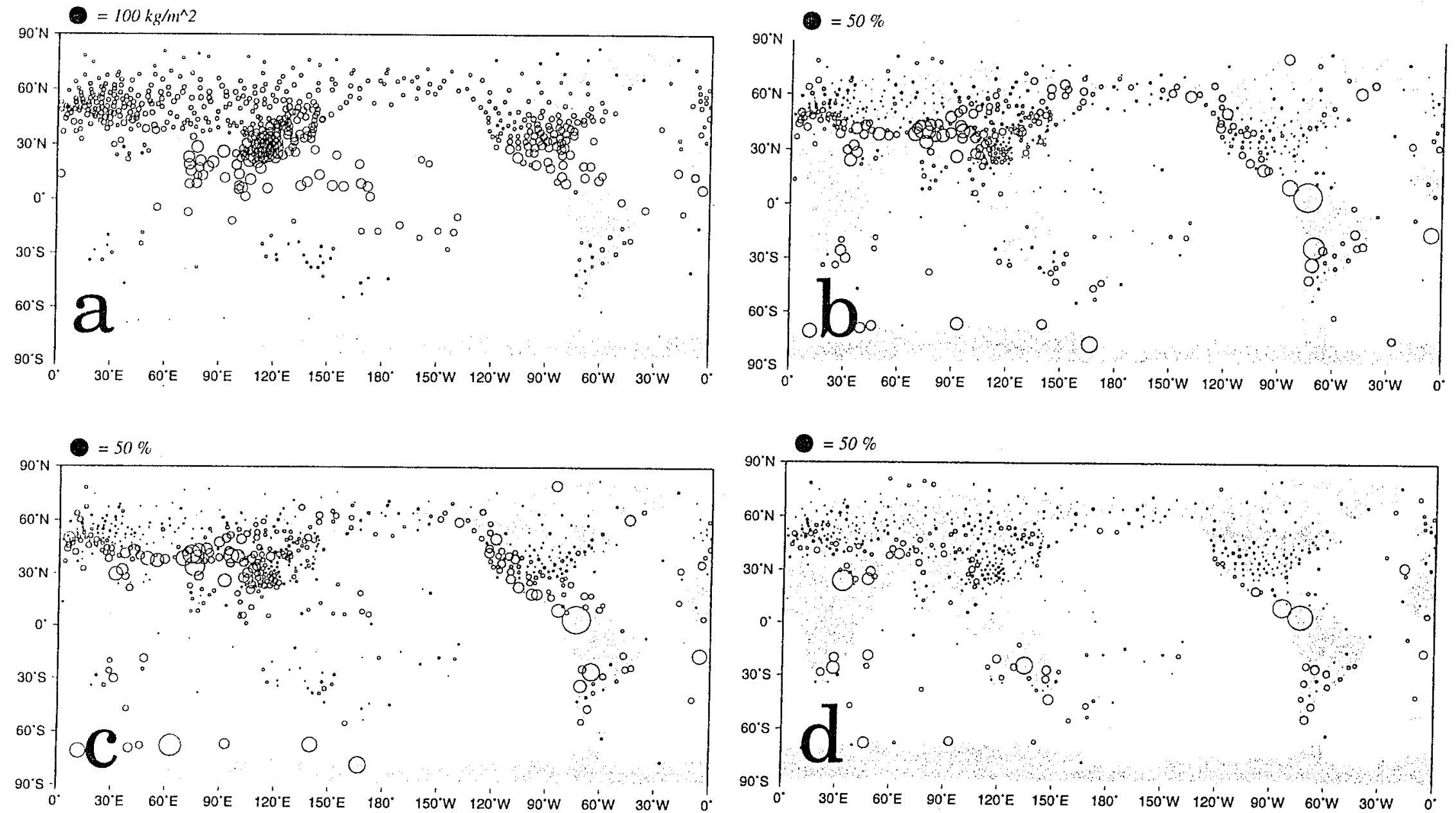

Figure 2. Mean July precipitable water values for (a) Ross and Elliott Sonde data. The values are indicated by the size of the circle shown above the left hand side of the frame.(b) The difference of the ERA minus the Ross and Elliott precipitable water, normalized by the radiosonde value and expressed as a percent. The values are indicated by the size of the circle scale shown above the left hand side of the frame. Blue indicates negative values, red indicates positive values.(c) As in (b) except for the NCEP reanalysis (d) As in (b) except for the NVAP data set. 

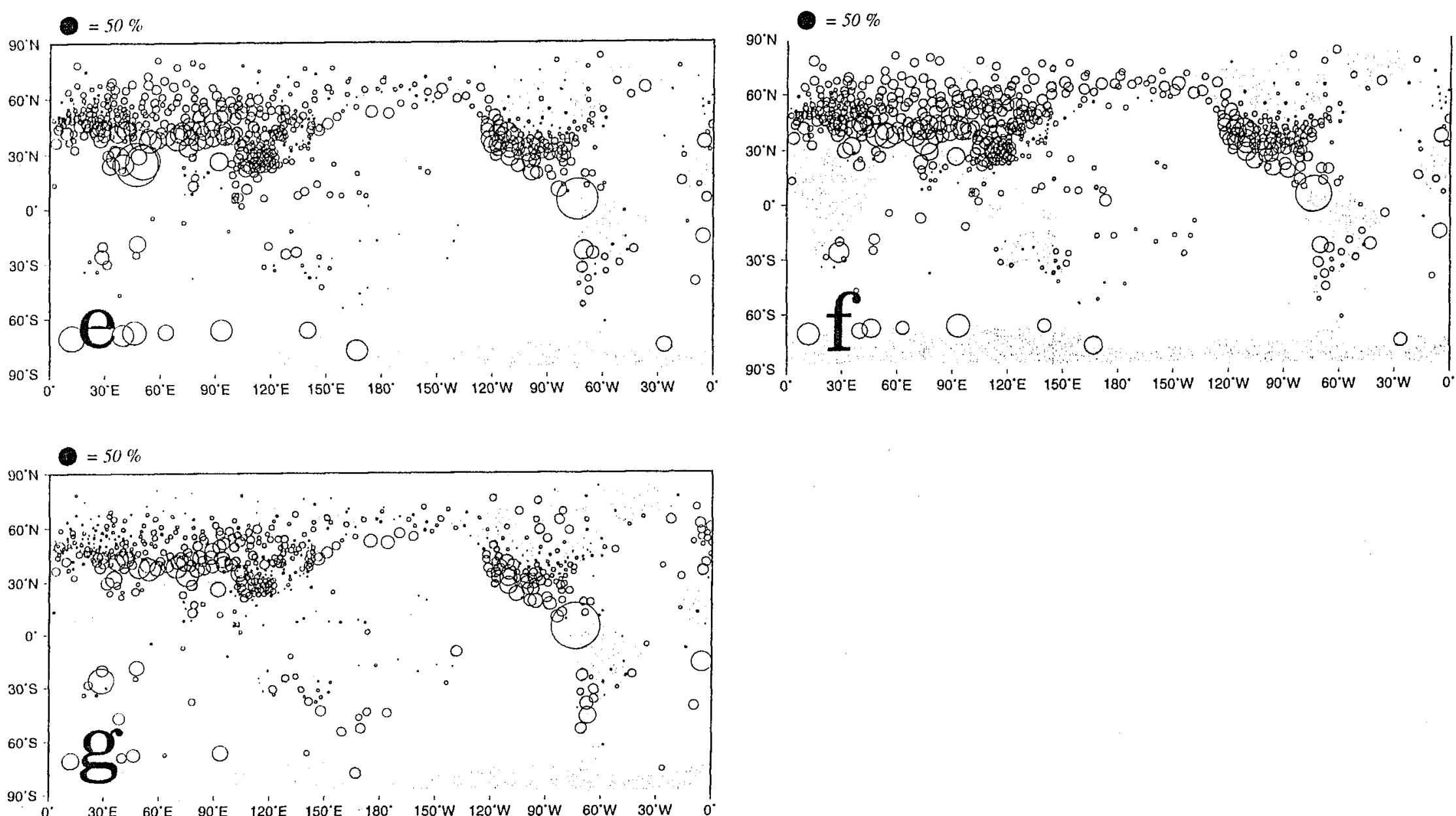

Figure 2, (cont'd) (e) As in (b)except for the CCM3 AMIP integration.(f) As in (b) except for the CSM control integration(g) As in (b) except for the $\mathrm{CSM} 1 \%$ per year $\mathrm{CO}_{2}$ increase experiment. 

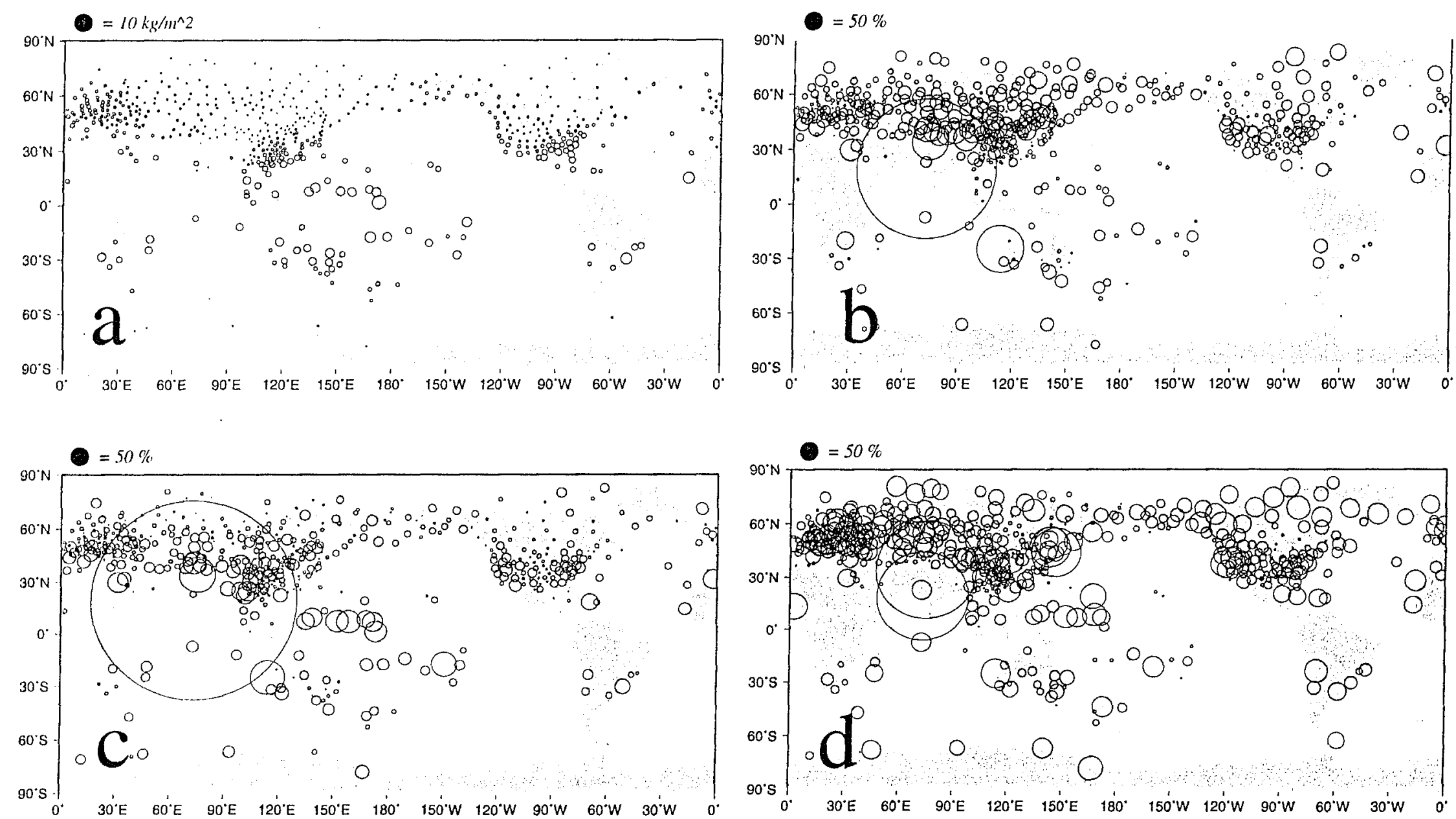

Figure 3. Standard deviation of January precipitable water values for (a) Ross and Elliott Sonde data. The values are indicated by the size of the circle shown above the left hand side of the frame.

(b) The difference of the ERA minus the Ross and Elliott precipitable water, normalized by the radiosonde value and expressed as a percent. The values are indicated by the size of the circle scale shown above the left hand side of the frame. Blue indicates negative values, red indicates positive values.(c) As in (b) except for the NCEP reanalysis(d) As in (b) except for the NVAP data set. 

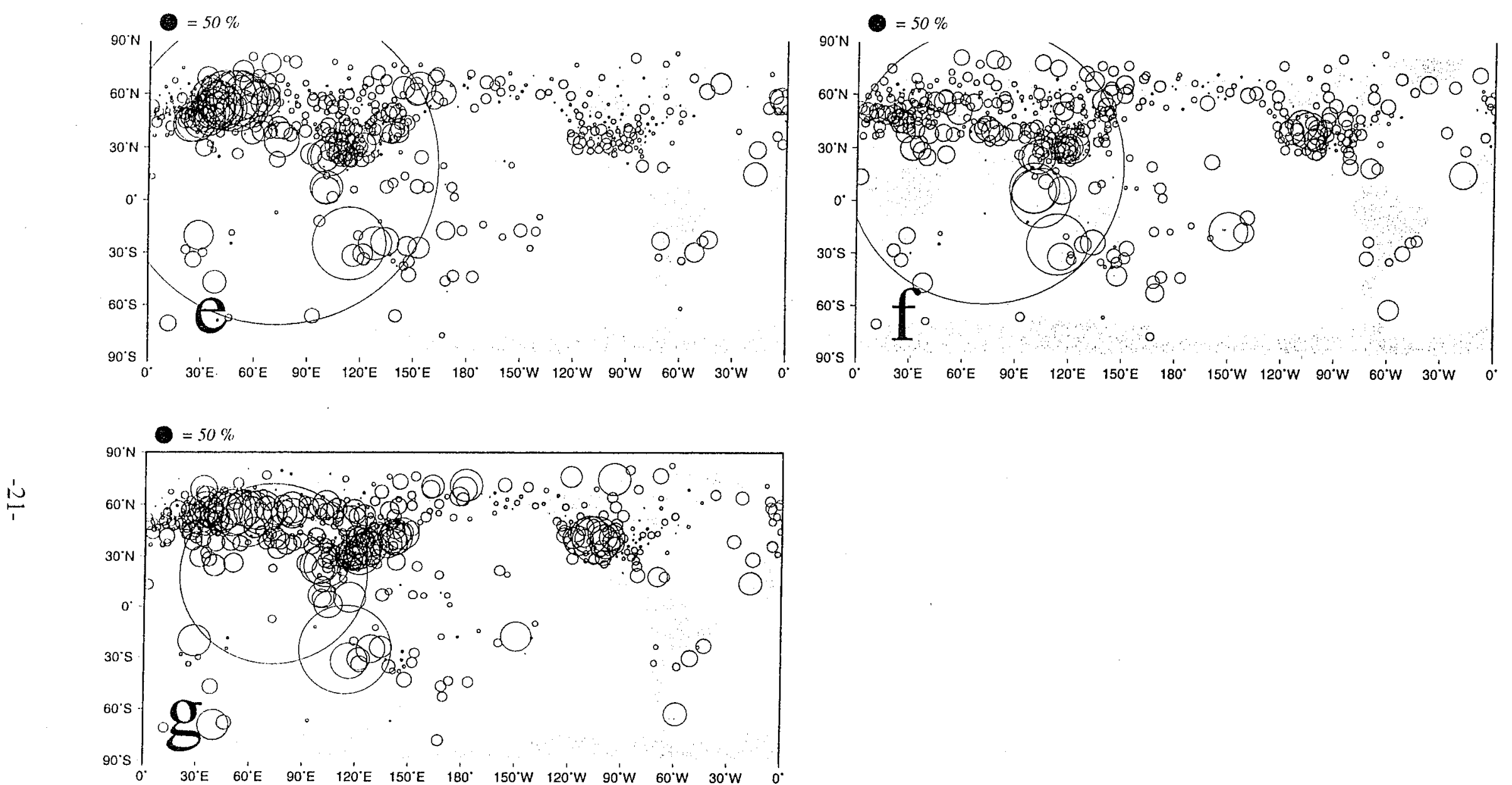

Figure 3. (cont'd) (e) As in (b)except for the CCM3 AMIP integration. (f) As in (b) except for the CSM control integration

(g) As in (b) except for the CSM $1 \%$ per year $\mathrm{CO}_{2}$ increase experiment. 

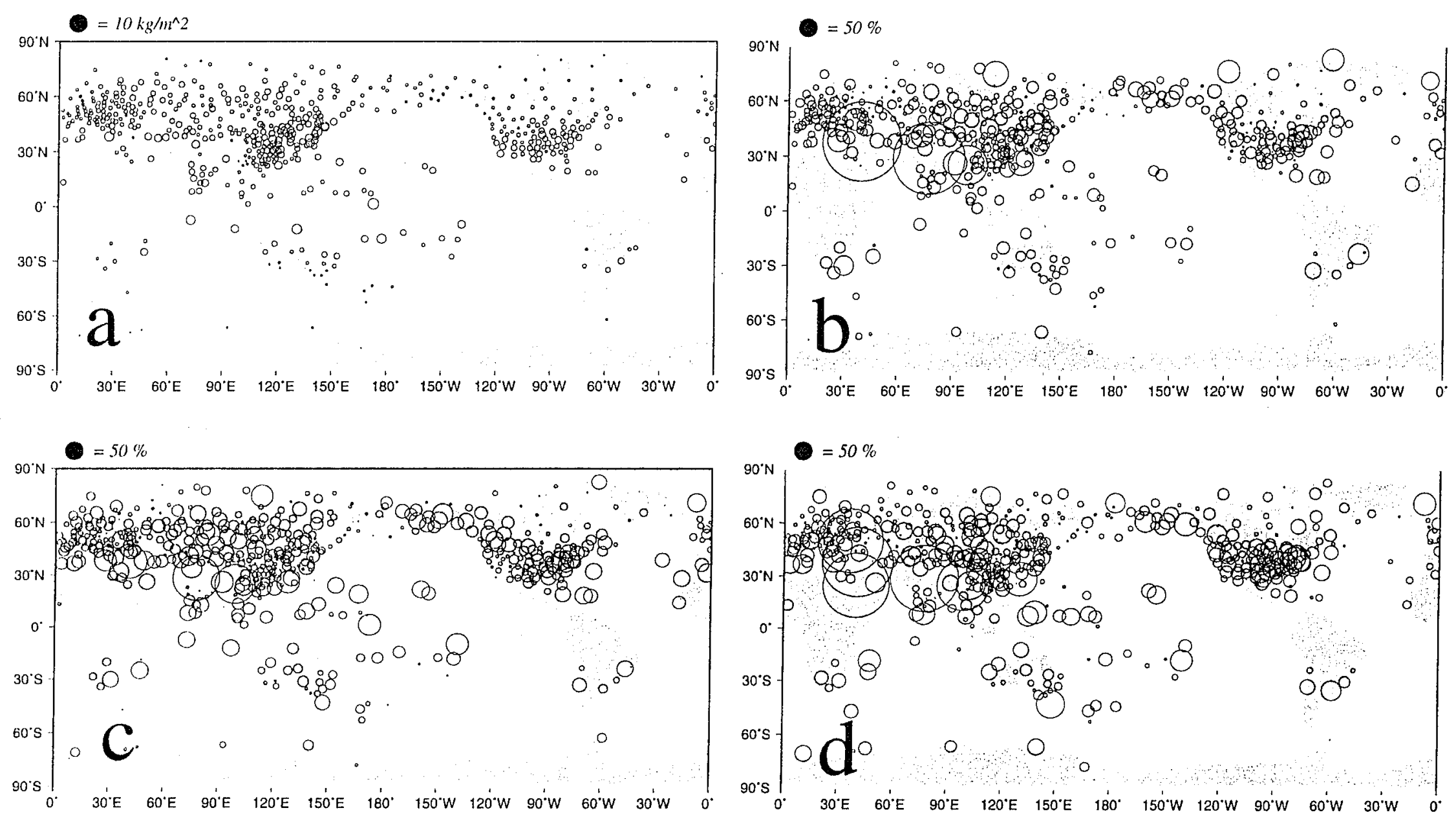

Figure 4. Standard Deviation of July precipitable water values for (a) Ross and Elliott Sonde data. The values are indicated by the size of the circle shown above the left hand side of the frame.

(b) The difference of the ERA minus the Ross and Elliott precipitable water, normalized by the radiosonde value and expressed as a percent. The values are indicated by the size of the circle scale shown above the left hand side of the frame. Blue indicates negative values, red indicates positive values.(c) As in (b) except for the NCEP reanalysis.(d) As in (b) except for the NVAP data set. 

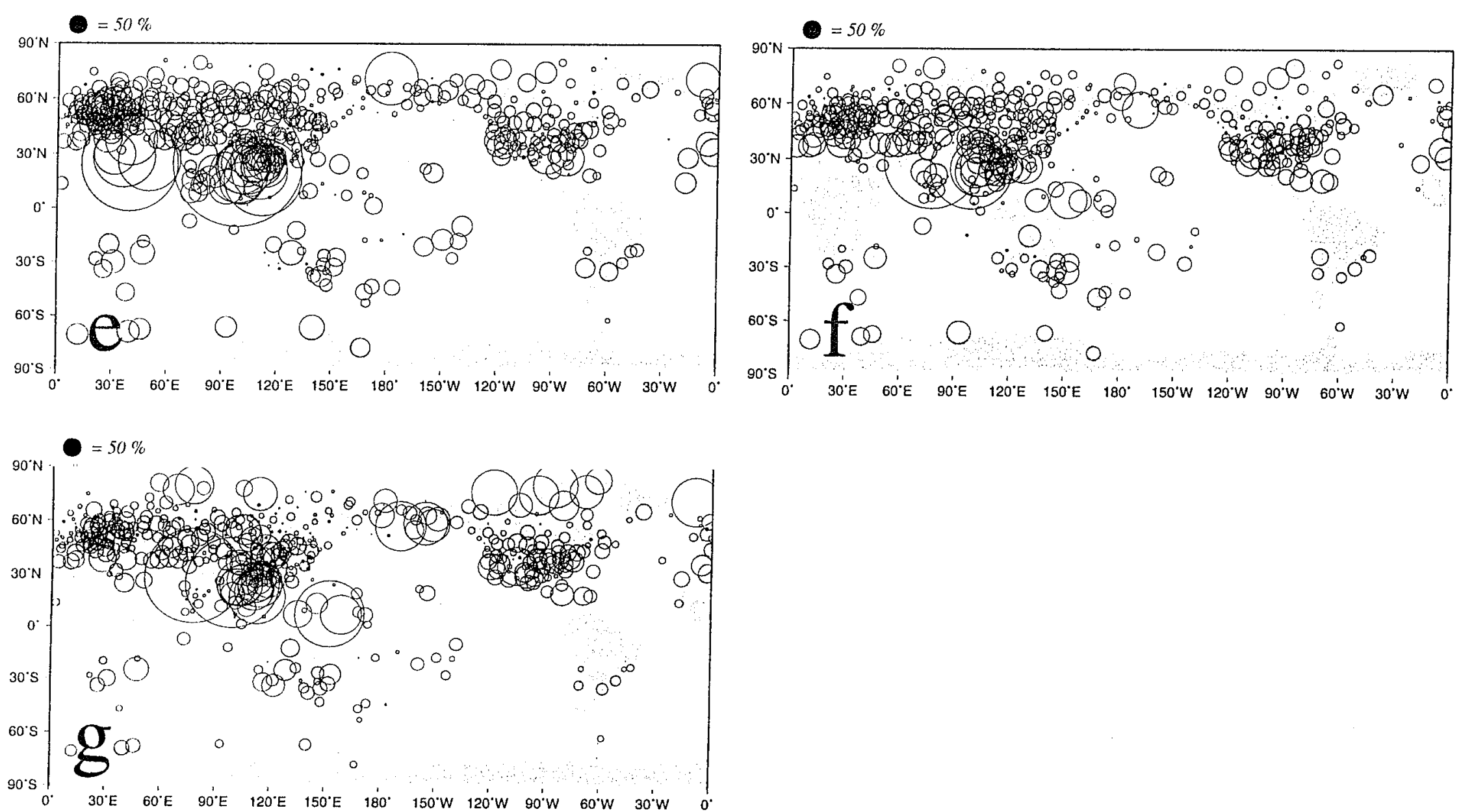

(e) As in (b)except for the CCM3 AMIP integration.

(f) As in (b) except for the CSM control integration

(g) As in (b) except for the CSM $1 \%$ per year $\mathrm{CO}_{2}$ increase experiment. 

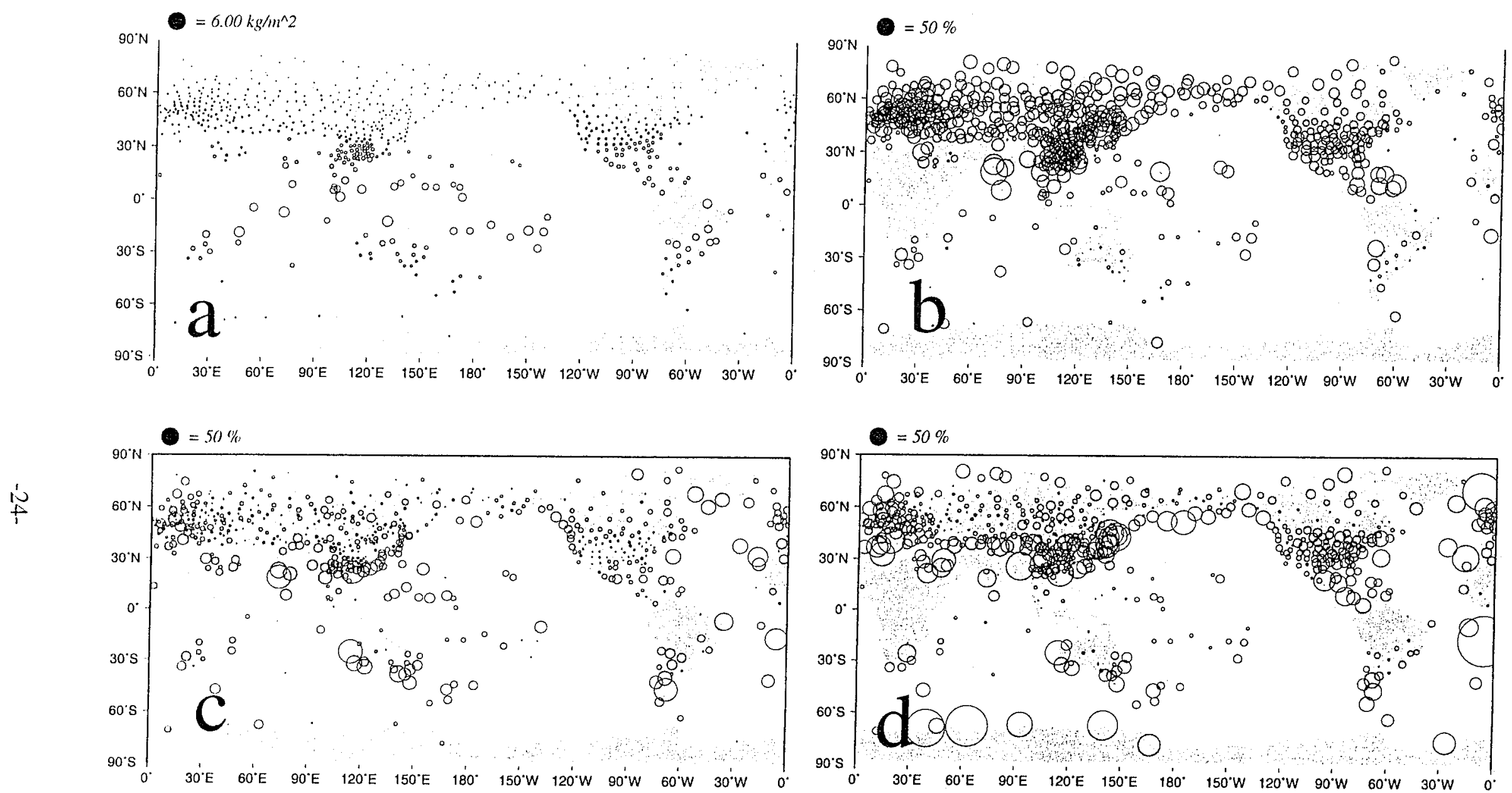

Figure 5. Mean January precipitable water in the 500 to $300 \mathrm{hPa}$ layer values for (a) Ross and Elliott Sonde data. The values are indicated by the size of the circle shown above the left hand side of the frame.

(b) The difference of the ERA minus the Ross and Elliott precipitable water, normalized by the radiosonde value and expressed as a percent. The values are indicated by the size of the circle scale shown above the left hand side of the frame. Blue indicates negative values, red indicates positive values. (c) As in (b) except for the NCEP reanalysis.(d) As in (b) except for the NVAP data set. 

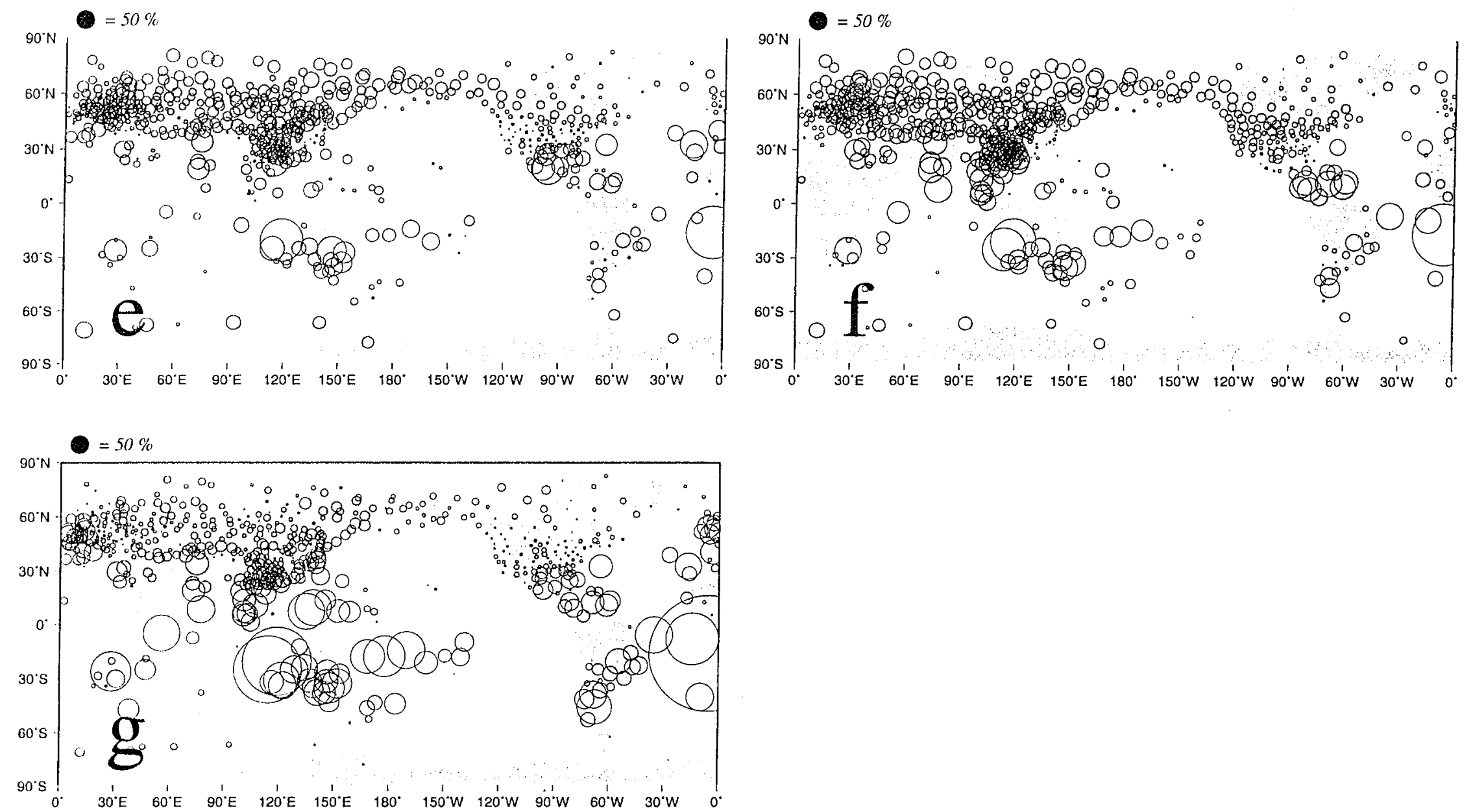

(e) As in (b)except for the CCM3 AMIP integration.

(f) As in (b) except for the CSM control integration

(g) As in (b) except for the CSM $1 \%$ per year $\mathrm{CO}_{2}$ increase experiment. 

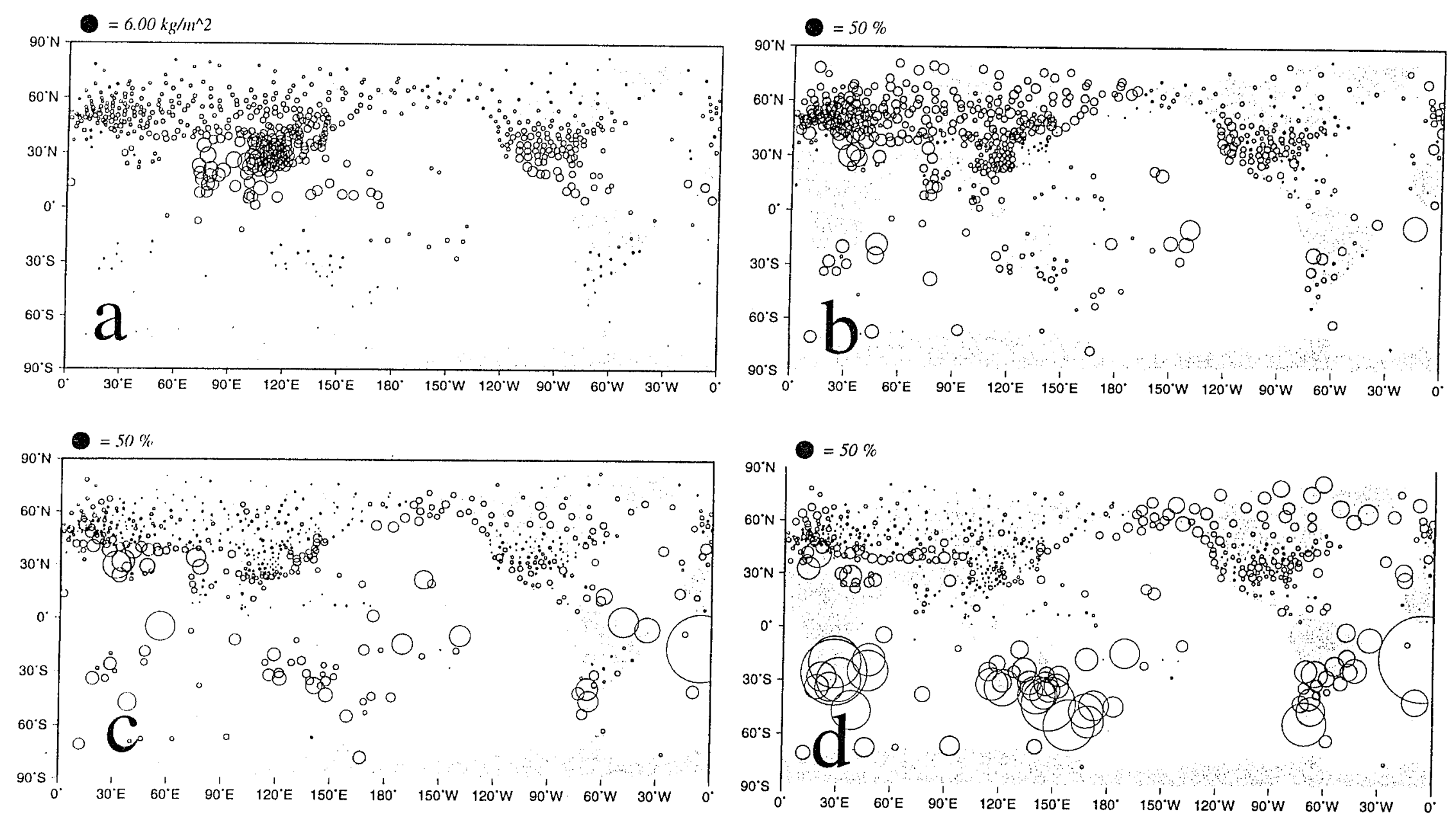

Figure 6. Mean July precipitable water valuesin the $500 \mathrm{ri} 300 \mathrm{hPa}$ layer for (a) Ross and Elliott Sonde data. The values are indicated by the size of the circle shown above the left hand side of the frame.

(b) The difference of the ERA minus the Ross and Elliott precipitable water, normalized by the radiosonde value and expressed as a percent. The values are indicated by the size of the circle scale shown above the left hand side of the frame. Blue indicates negative values, red indicates positive values. (c) As in (b) except for the NCEP reanalysis.(d) As in (b) except for the NVAP data set. 

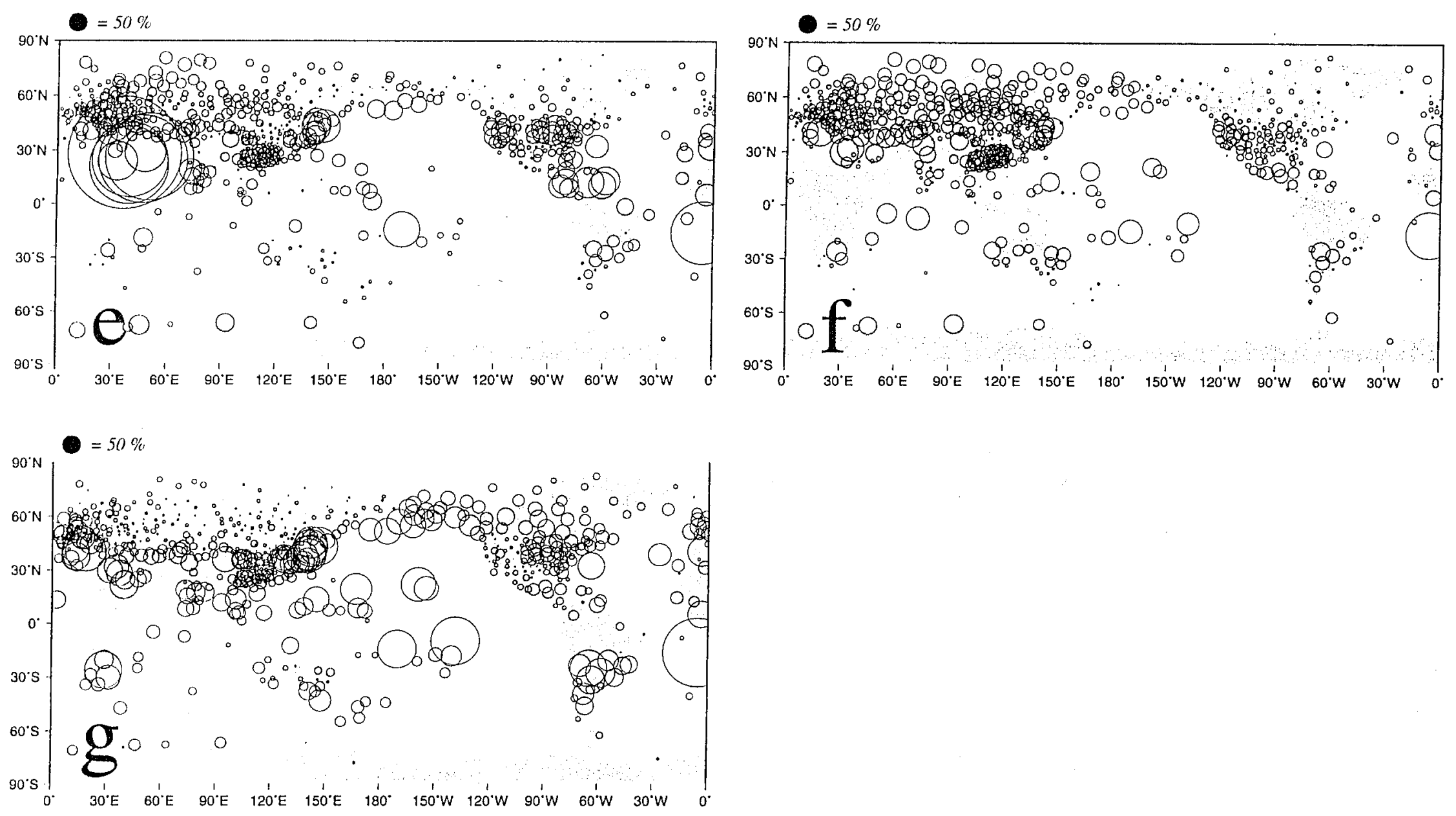

(e) As in (b)except for the CCM3 AMIP integration.

(f) As in (b) except for the CSM control integration

(g) As in (b) except for the CSM $1 \%$ per year $\mathrm{CO}_{2}$ increase experiment. 

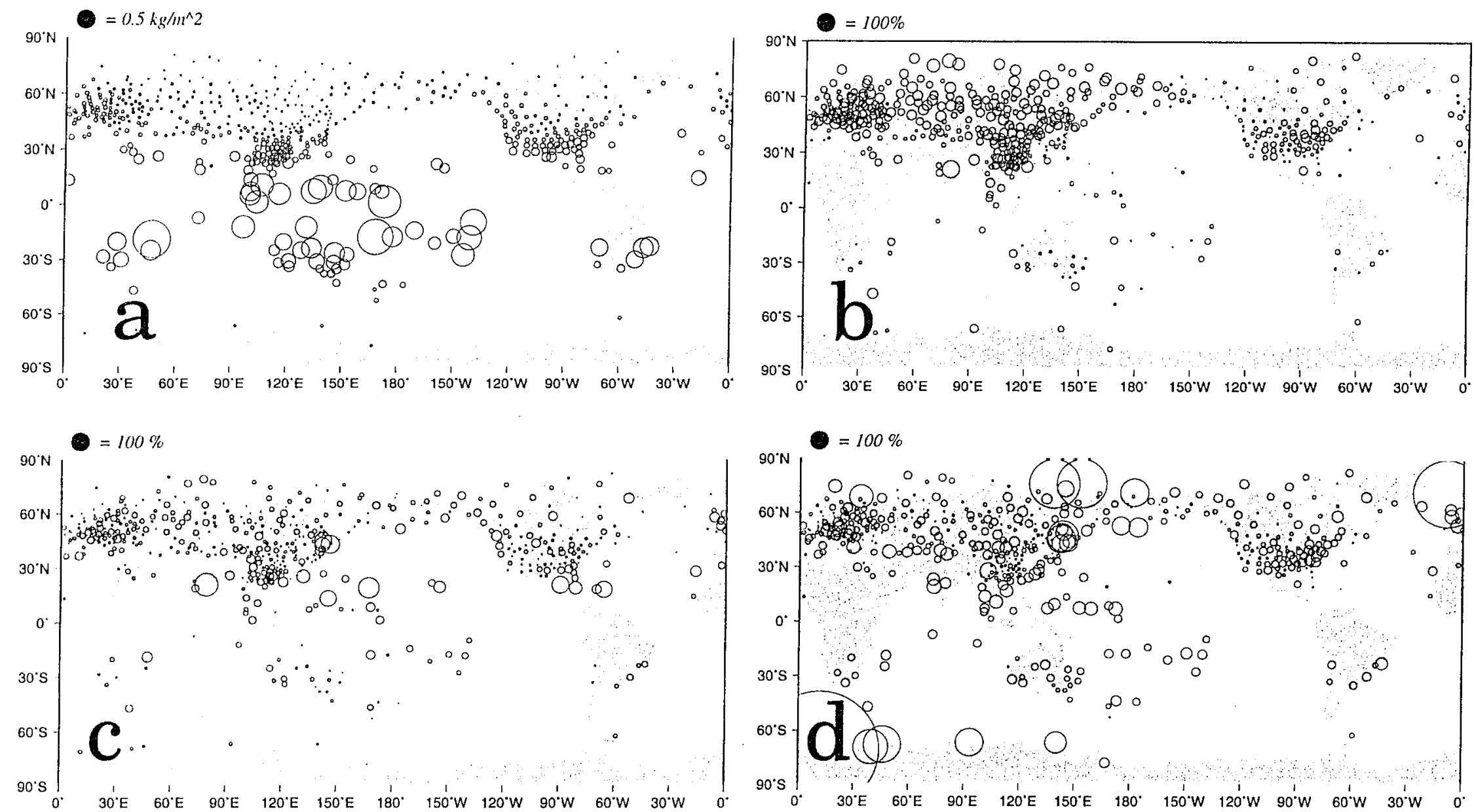

Figure 7. Standard deviation of January precipitable water in the 500 to $300 \mathrm{hPa}$ layer for (a) Ross and Elliott Sonde data. The values are indicated by the size of the circle shown above the left hand side of the frame.

(b) The difference of the ERA minus the Ross and Elliott precipitable water, normalized by the radiosonde value and expressed as a percent. The values are indicated by the size of the circle scale shown above the left hand side of the frame. Blue indicates negative values, red indicates positive values. (c) As in (b) except for the NCEP reanalysis.(d) As in (b) except for the NVAP data set. 

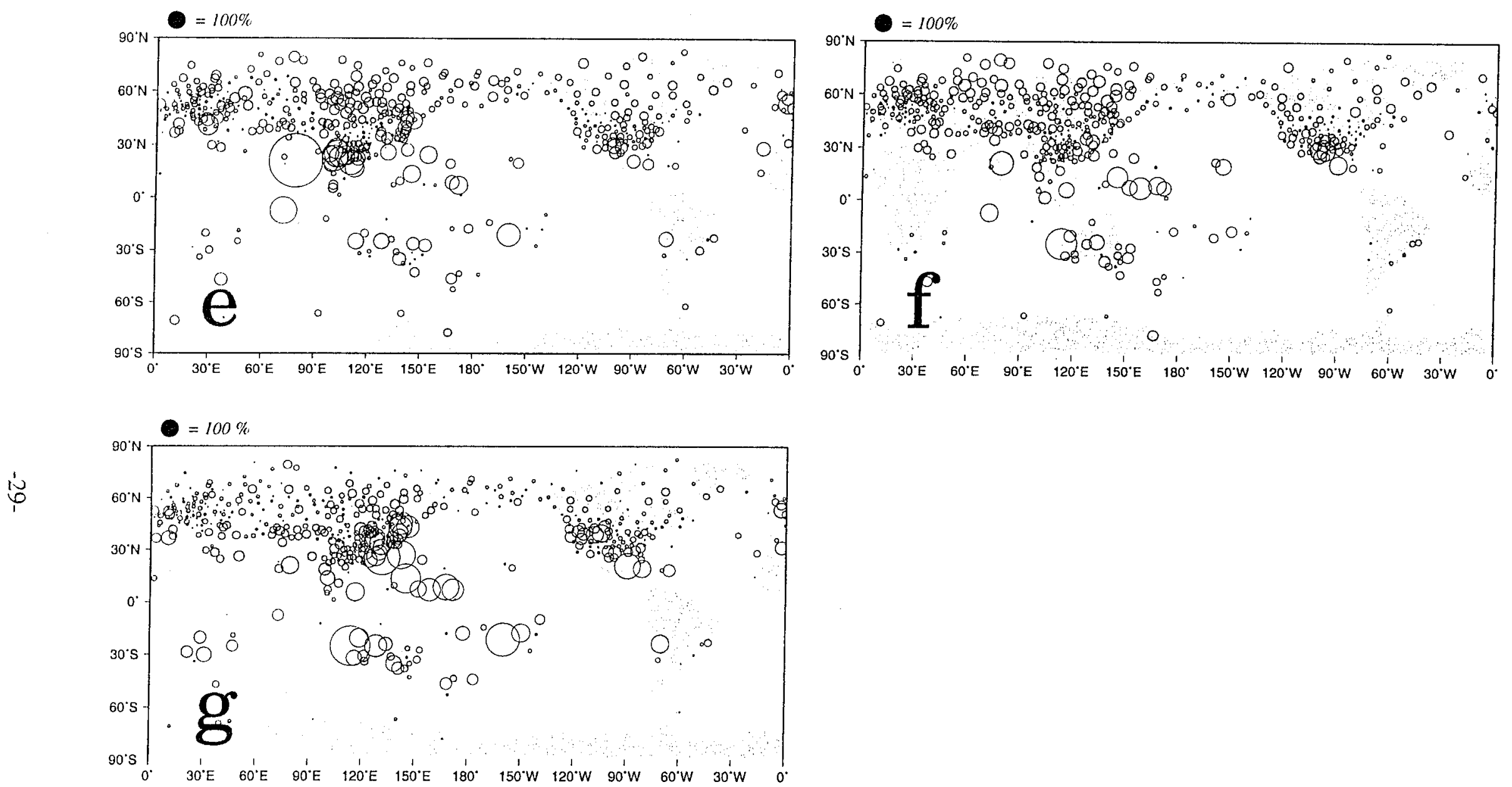

Figure 7. (cont'd) (e) As in (b)except for the CCM3 AMIP integration.

(f) As in (b) except for the CSM control integration

(g) As in (b) except for the CSM $1 \%$ per year $\mathrm{CO}_{2}$ increase experiment. 

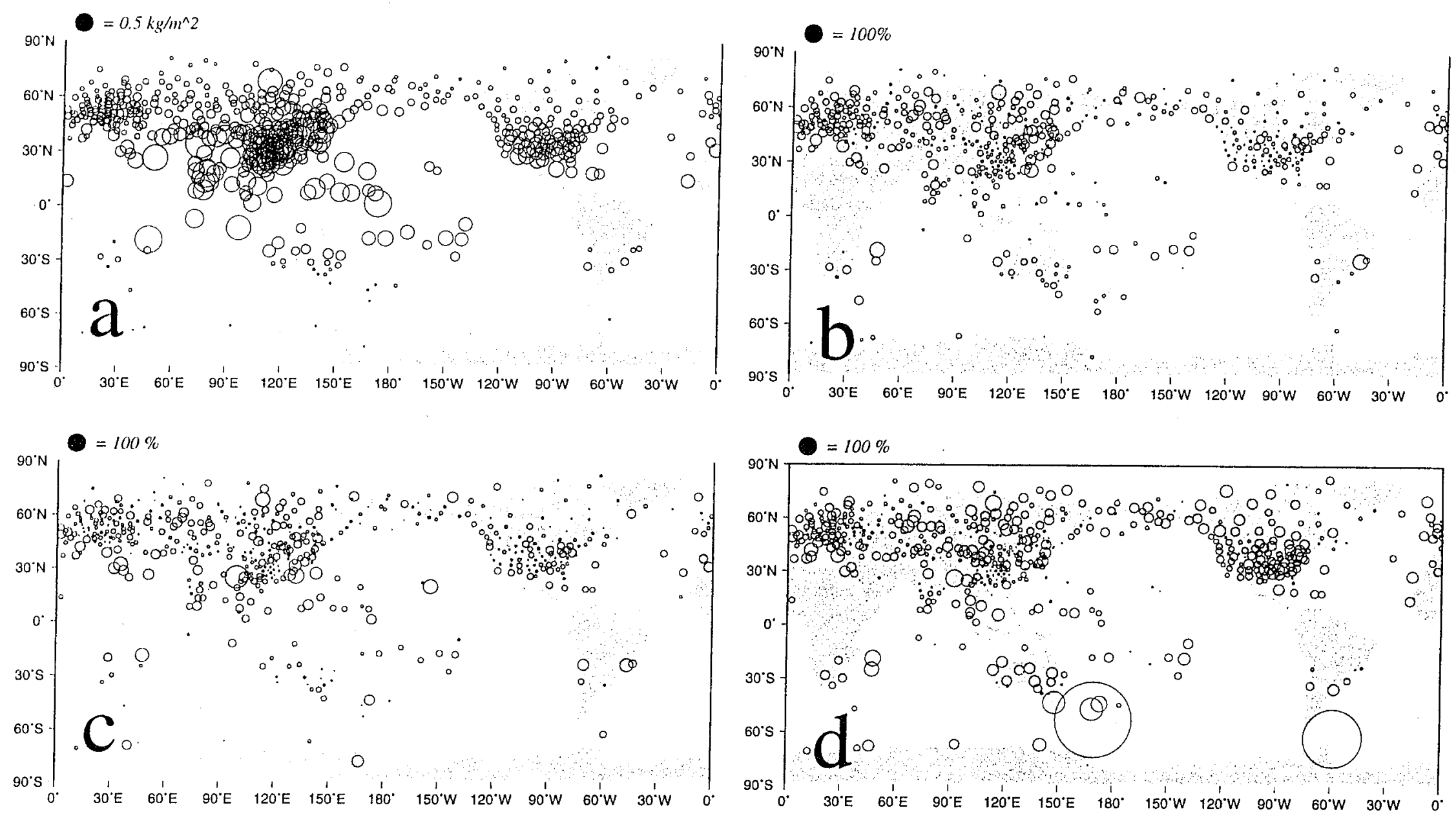

Figure 8. Standard deviation of the July precipitable water in the 500 to $300 \mathrm{hPa}$ layer for (a) Ross and Elliott Sonde data. The values are indicated by the size of the circle shown above the left hand side of the frame.

(b) The difference of the ERA minus the Ross and Elliott precipitable water, normalized by the radiosonde value and expressed as a percent. The values are indicated by the size of the circle scale shown above the left hand side of the frame. Blue indicates negative values, red indicates positive values. (c) As in (b) except for the NCEP reanalysis.(d) As in (b) except for the NVAP data set. 

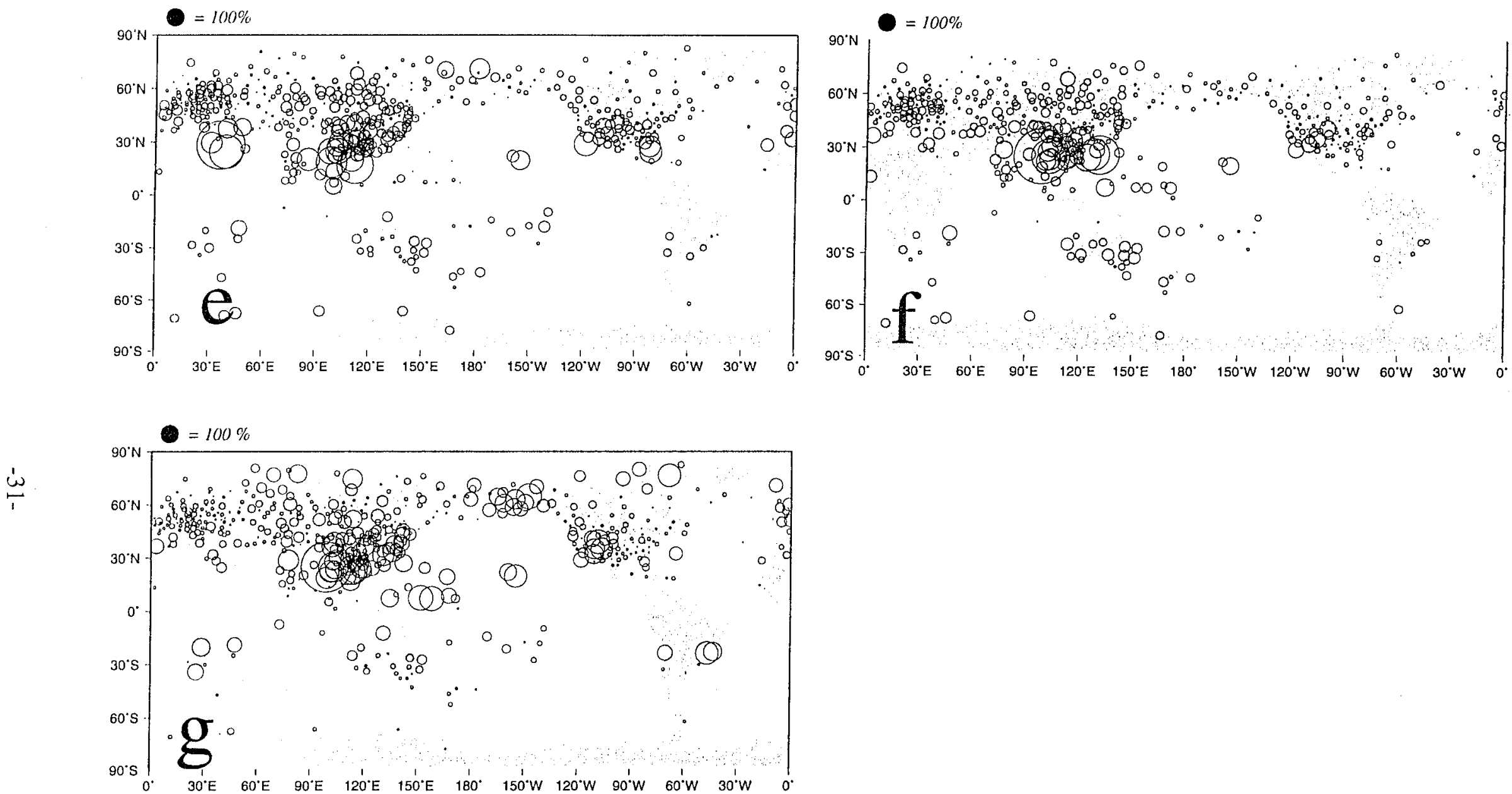

Figure 8. (cont'd) (e) As in (b)except for the CCM3 AMIP integration. (f) As in (b) except for the CSM control integration

(g) As in (b) except for the CSM $1 \%$ per year $\mathrm{CO}_{2}$ increase experiment. 

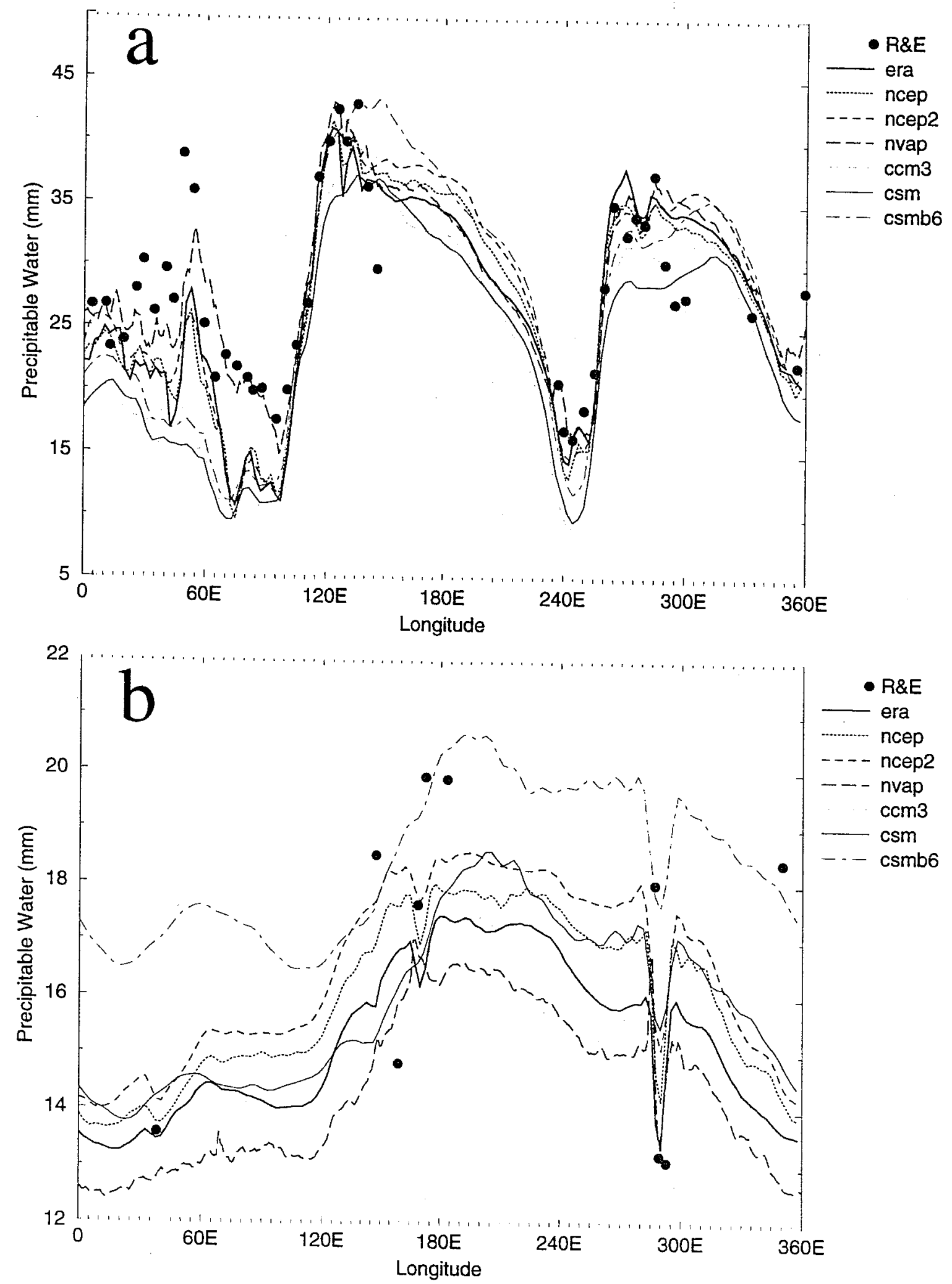

Figure 9. (a)Total precipitable water for July averaged from $35 \mathrm{~N}$ to $45 \mathrm{~N}$ about the globe for all the data sets. The black dots indicate the Ross and Elliott sonde data, which was binned into 5 degree longitude bands before averaging. (b) As in (a) except for January and $60 \mathrm{~S}$ to $40 \mathrm{~S}$. 

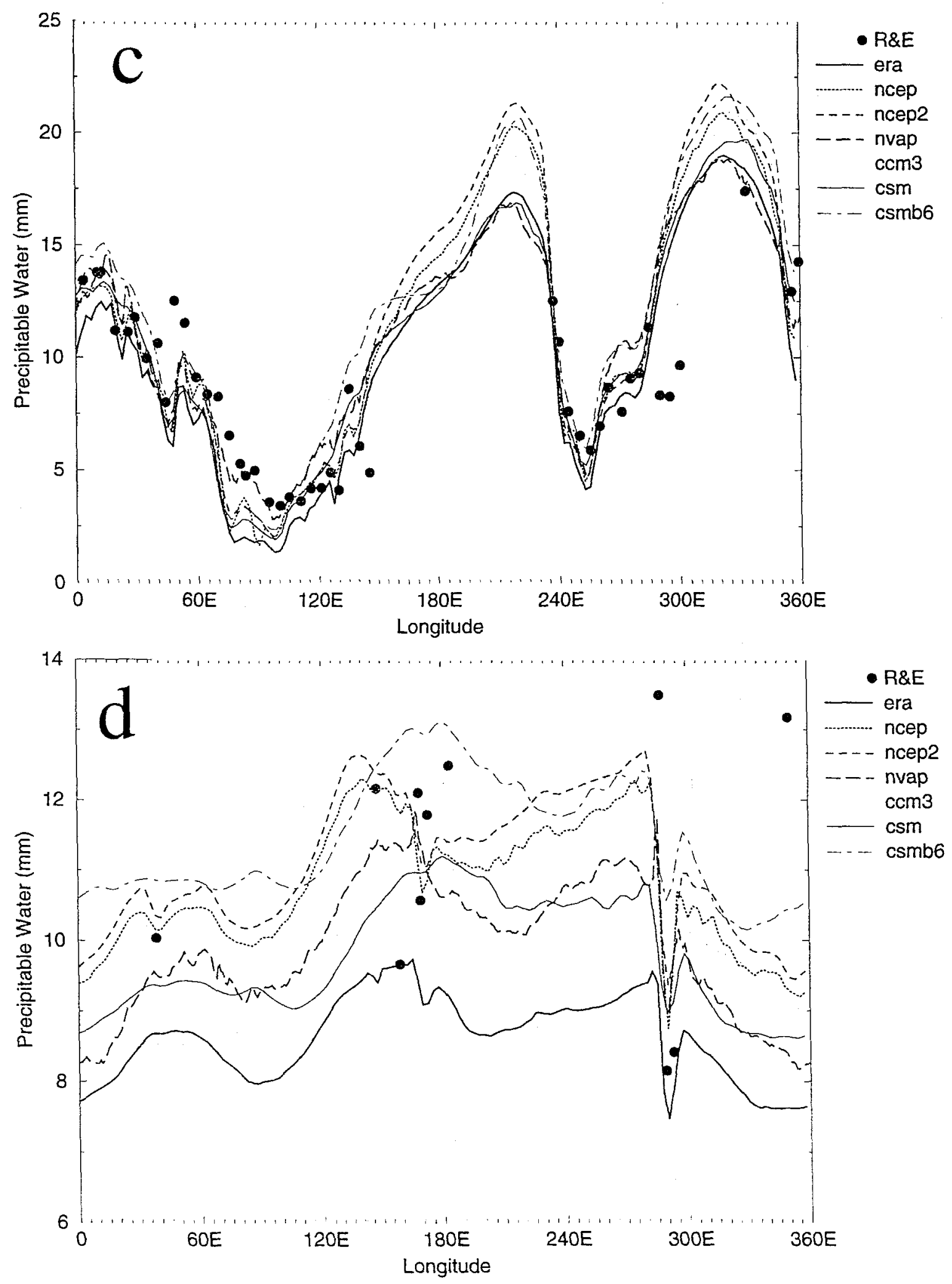

Figure 9. (continued)(c) As in (a) except for January.

(d) As in (b) except for July. 

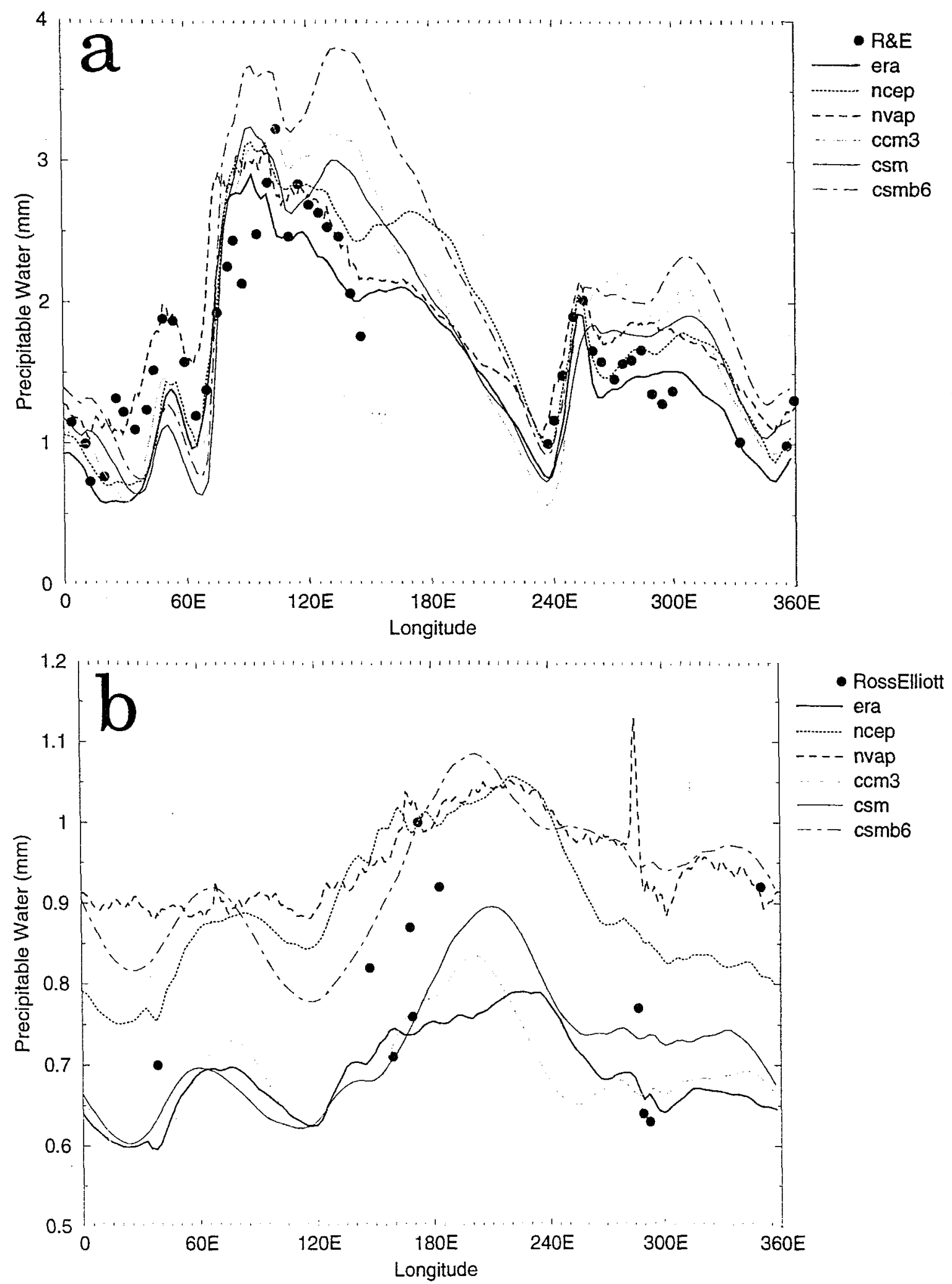

Figure 10. Precipitable water in the 500 to $300 \mathrm{hPa}$ layer for July averaged from $35 \mathrm{~N}$ to $45 \mathrm{~N}$ about the globe for all the data sets. The black dots indicate the Ross and Elliott sonde data, which was binned into 5 degree longitude bands before averaging. (b) As in (a) except for January and 60S to $40 \mathrm{~S}$. 

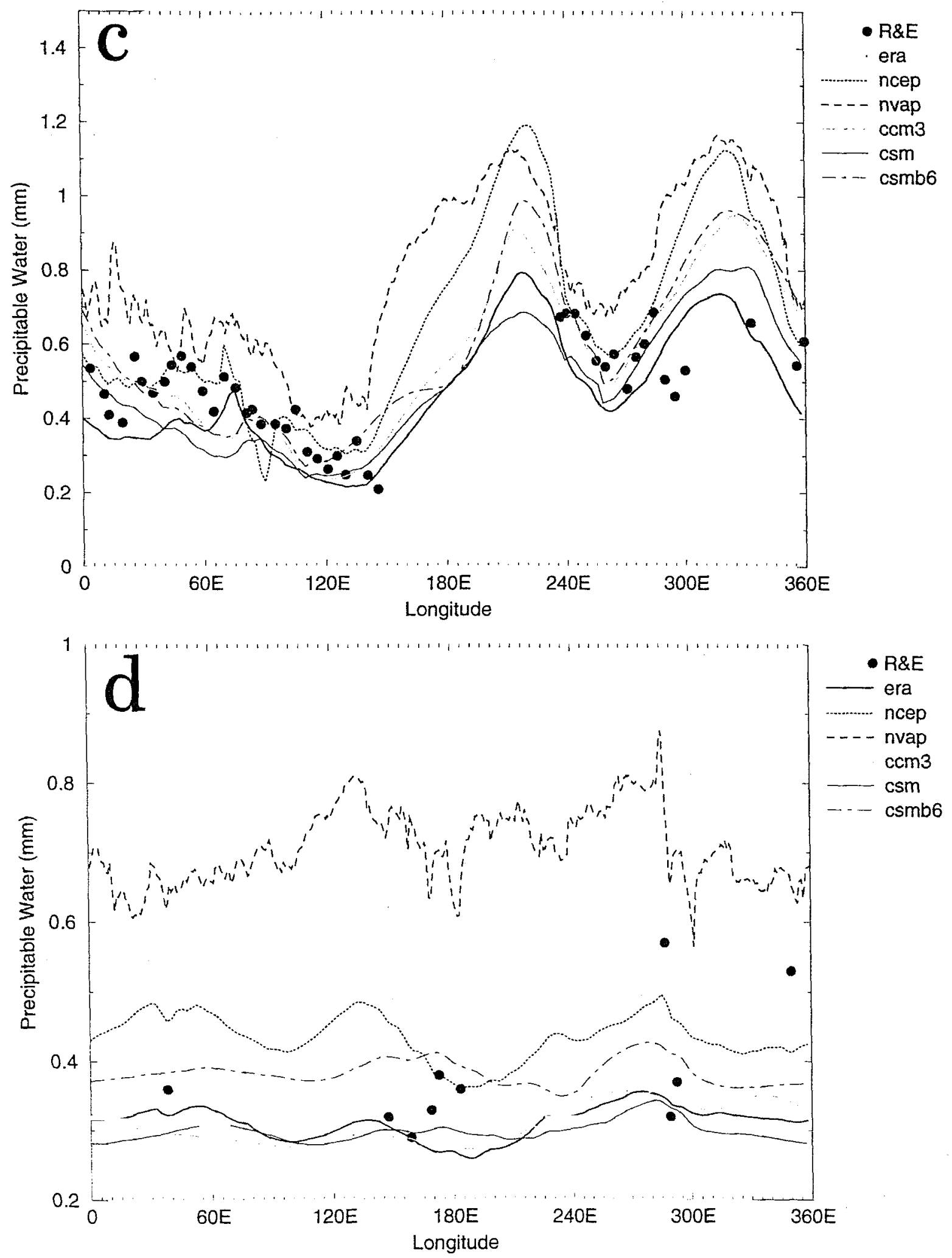

Figure 10. continued (c) As in (a) except for January.

(d) As in (b) except for July. 

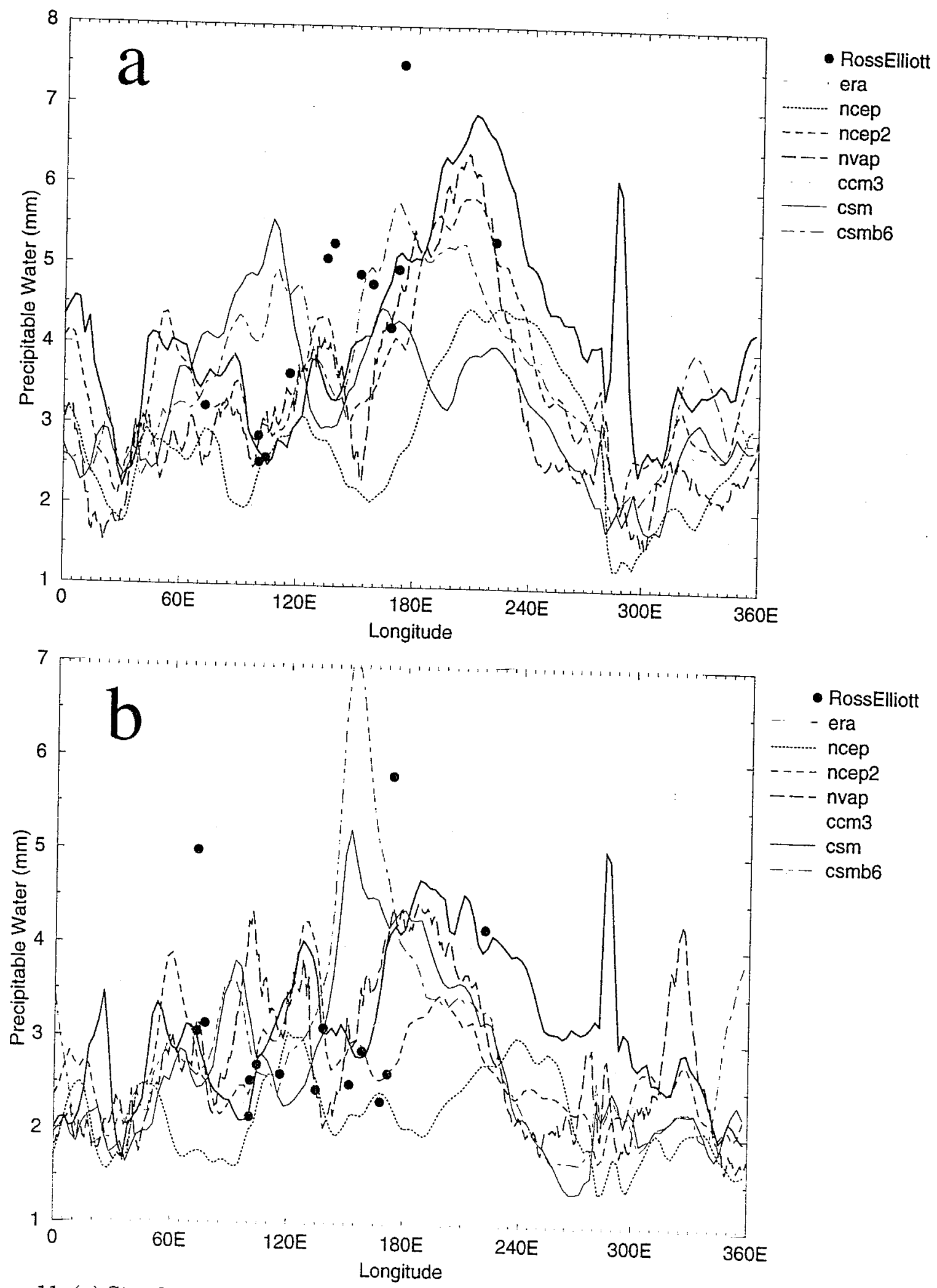

Figure 11. (a) Standard deviation of total precipitable water for January averaged from $10 \mathrm{~S}$ to $10 \mathrm{~N}$ about the globe for all the data sets. The black dots indicate the Ross and Elliott sonde data, which was binned into 5 degree longitude bands before averaging. (b) As in (a) except for July. 

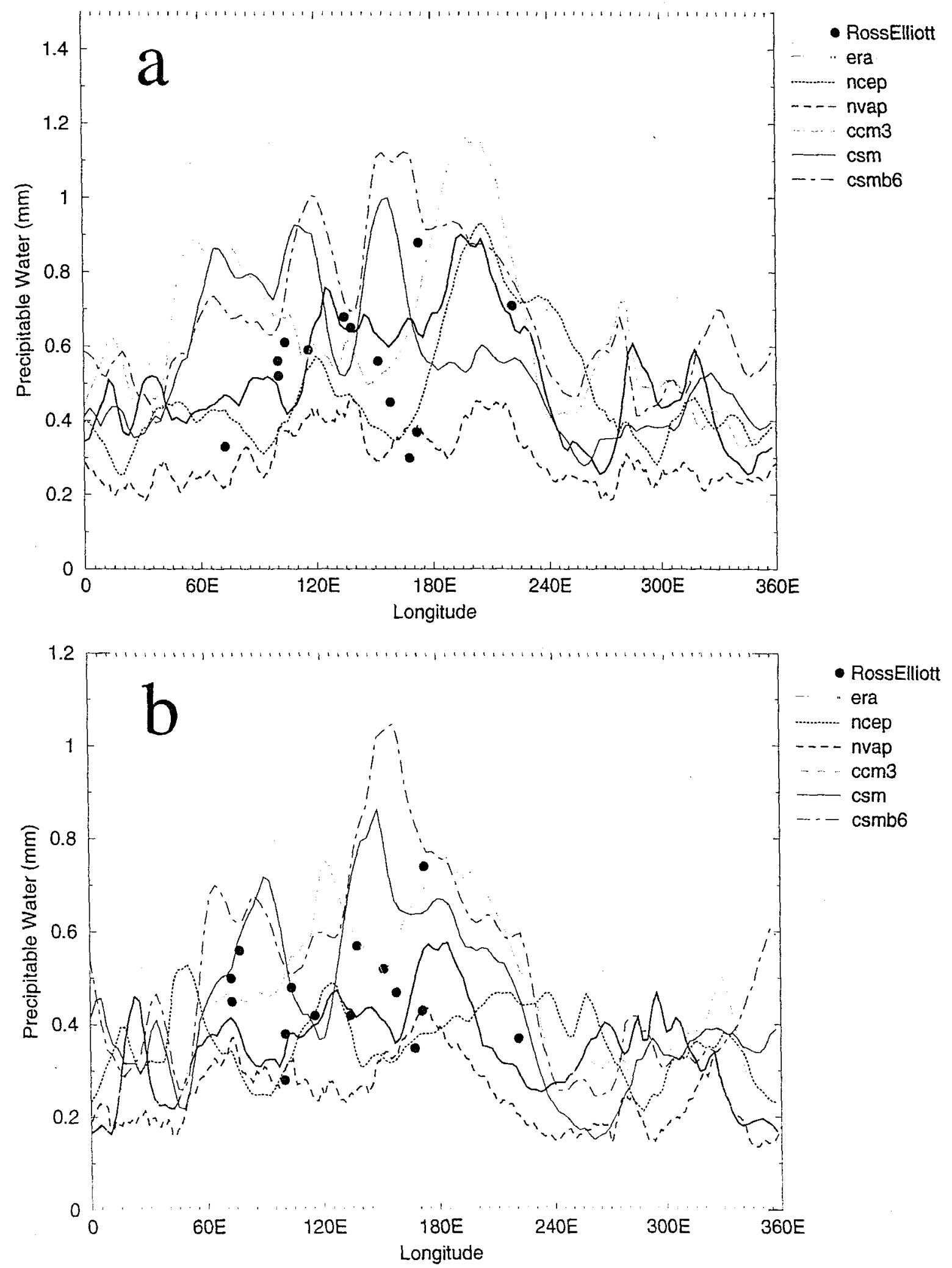

Figure 12. (a) Standard deviation of precipitable water in the 500 to $300 \mathrm{hPa}$ layer for January averaged from $10 \mathrm{~S}$ to $10 \mathrm{~N}$ about the globe. The black dots indicate the Ross and Elliott sonde data, which was binned into 5 degree longitude bands before averaging. (b) As in (a) except for July. 

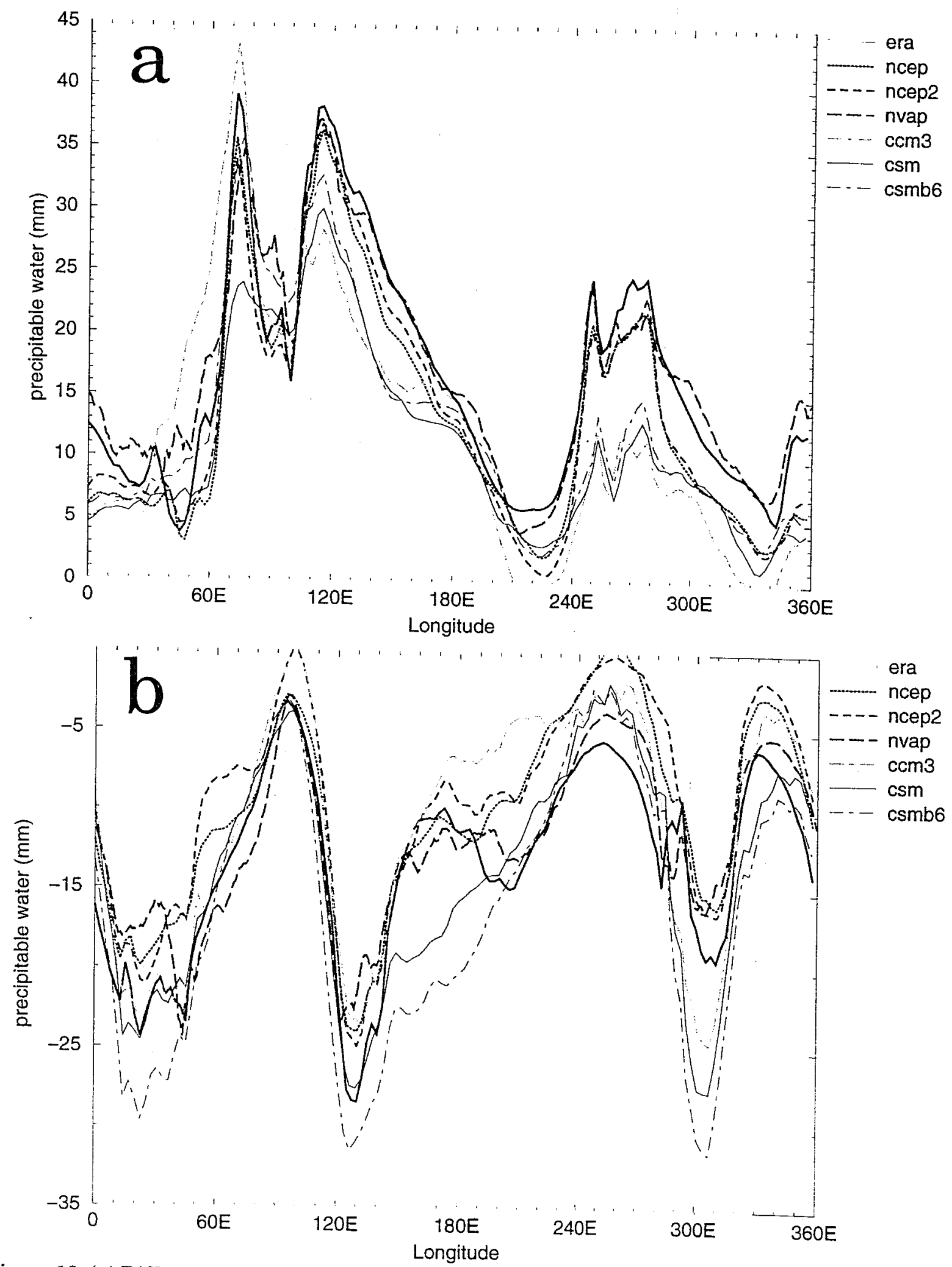

Figure 13. (a) Difference between July and January total precipitable water averaged from $25 \mathrm{~N}$ to $35 \mathrm{~N}$ for all the gridded data sets.

(b) As in (a) except for $20 \mathrm{~S}$ to $10 \mathrm{~S}$. 

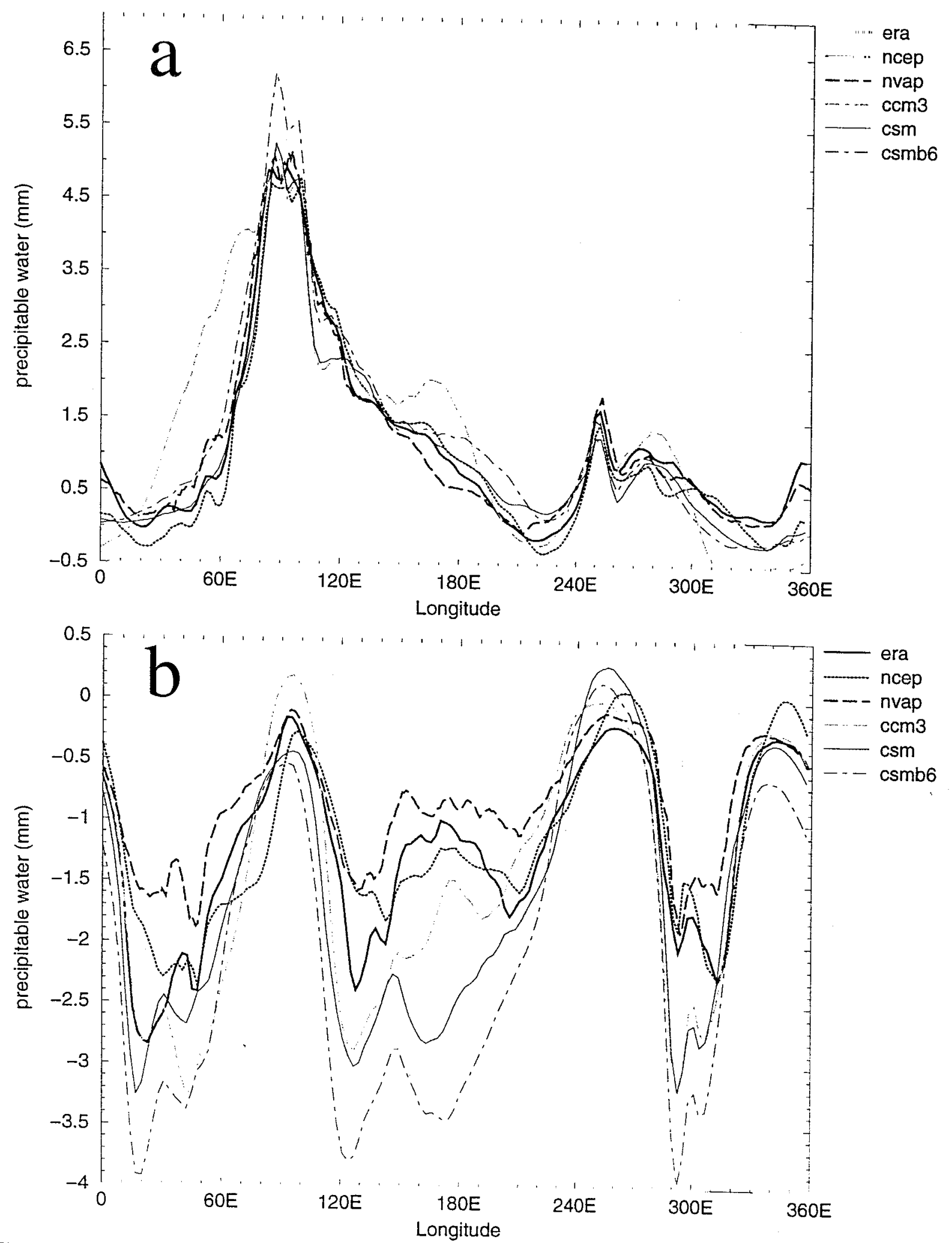

Figure 14. (a) Difference between July and January precipitable water in the 500 to $300 \mathrm{hPa}$ layer averaged from $25 \mathrm{~N}$ to $35 \mathrm{~N}$ for all the gridded data sets.

(b) As in (a) except for $20 \mathrm{~S}$ to $10 \mathrm{~S}$. 

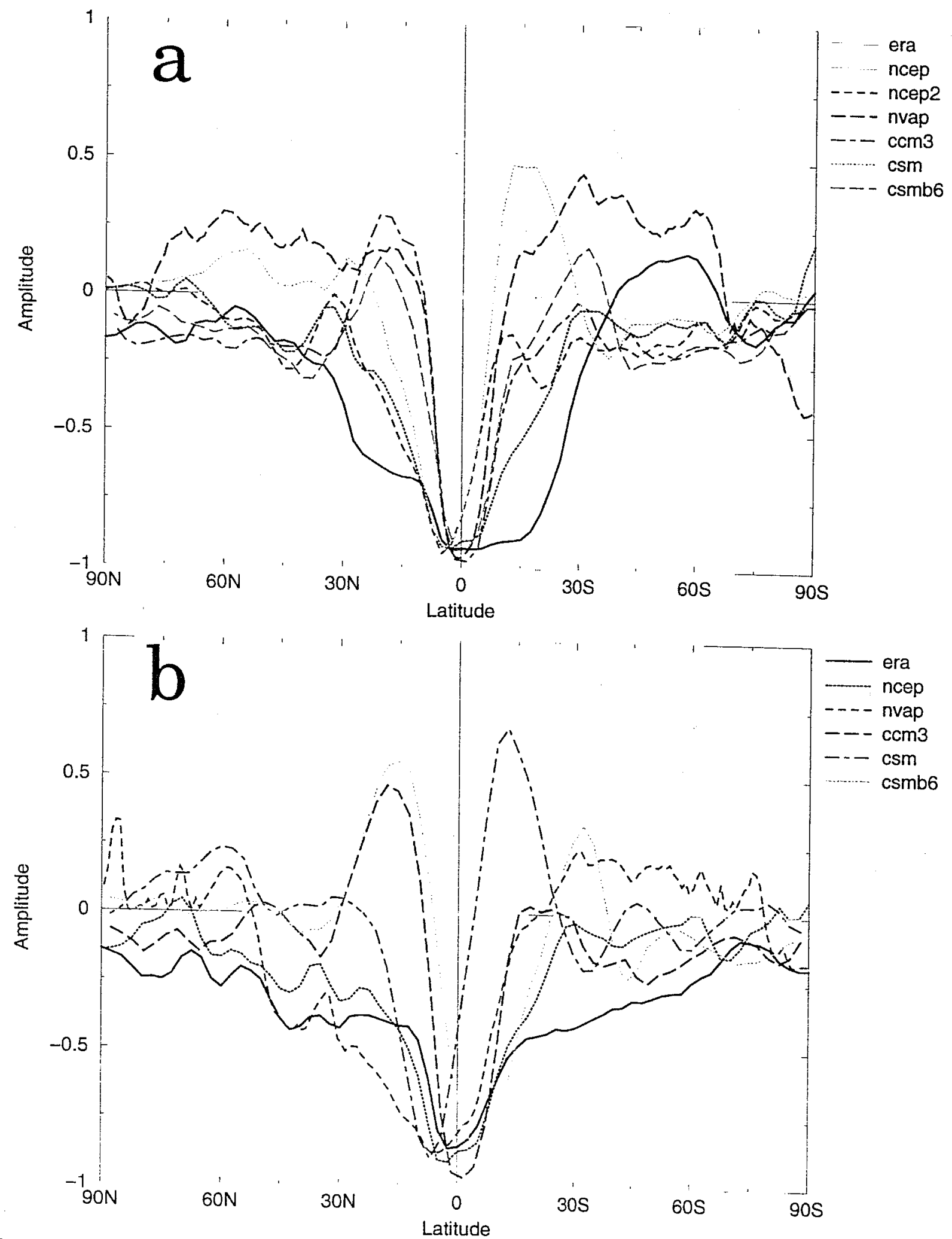

Figure 15. (a) Leading EOF of the interannual variations of the zonally averaged total precipitable water for all the gridded data sets. The percent variance explained by this leading mode is given in Table 1. (b) As in (a) except for the precipitable water in the 500 to $300 \mathrm{hPa}$ layer 